\title{
An investigation into seasonal and regional aerosol characteristics in East Asia using model-predicted and remotely-sensed aerosol properties
}

\author{
C. H. Song ${ }^{1, *}$, M. E. Park ${ }^{1}$, K. H. Lee ${ }^{1,3}$, H. J. Ahn ${ }^{1}$, Y. Lee ${ }^{1}$, J. Y. Kim², K. M. Han ${ }^{1}$, J. Kim ${ }^{4}$, Y. S. Ghim ${ }^{5}$, and \\ Y. J. Kim ${ }^{1}$ \\ ${ }^{1}$ Dept. of Environmental Science and Engineering, Gwangju Institute of Science and Technology (GIST), Gwangju, Korea \\ ${ }^{2}$ Hazardous Substance Research Center, Korea Institute of Science and Technology (KIST), Seoul, Korea \\ ${ }^{3}$ Earth System Science Interdisciplinary Center (ESSIC), University of Maryland, MD 20742, USA \\ ${ }^{4}$ Department of Atmospheric Science, Yonsei University, Seoul, Korea \\ ${ }^{5}$ Department of Environmental Science, Hankuk University of Foreign Studies, Yongin-si, Gyeonggi-do, Korea \\ *also at: Advanced Environmental Monitoring Research Center (ADEMRC), Gwangju Institute of Science and Technology \\ (GIST), Gwangju, Korea
}

Received: 25 January 2008 - Published in Atmos. Chem. Phys. Discuss.: 13 May 2008

Revised: 15 July 2008 - Accepted: 22 September 2008 - Published: 17 November 2008

\begin{abstract}
In this study, the spatio-temporal and seasonal distributions of EOS/Terra Moderate Resolution Imaging Spectroradiometer (MODIS)-derived aerosol optical depth (AOD) over East Asia were analyzed in conjunction with US EPA Models-3/CMAQ v4.3 modeling. In this study, two MODIS AOD products $\left(\tau_{\text {MODIS }}: \tau_{\text {M-BAER }}\right.$ and $\left.\tau_{\text {NASA }}\right)$ retrieved through a modified Bremen Aerosol Retrieval (MBAER) algorithm and NASA collection 5 (C005) algorithm were compared with the AOD $\left(\tau_{\mathrm{CMAQ}}\right)$ that was calculated from the US EPA Models-3/CMAQ model simulations. In general, the CMAQ-predicted AOD values captured the spatial and temporal variations of the two MODIS AOD products over East Asia reasonably well. Since $\tau_{\text {MODIS }}$ cannot provide information on the aerosol chemical composition in the atmosphere, different aerosol formation characteristics in different regions and different seasons in East Asia cannot be described or identified by $\tau_{\text {MODIS }}$ itself. Therefore, the seasonally and regionally varying aerosol formation and distribution characteristics were investigated by the US EPA Models-3/CMAQ v4.3 model simulations. The contribution of each particulate chemical species to $\tau_{\text {MODIS }}$ and $\tau_{\mathrm{CMAQ}}$ showed strong spatial, temporal and seasonal vari-
\end{abstract}

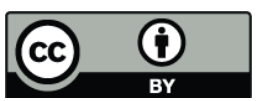

Correspondence to: $\mathrm{C}$. H. Song (chsong@gist.ac.kr) ations. For example, during the summer episode, $\tau_{\text {MODIS }}$ and $\tau_{\mathrm{CMAO}}$ were mainly raised due to high concentrations of $\left(\mathrm{NH}_{4}\right)_{2} \mathrm{SO}_{4}$ over Chinese urban and industrial centers and secondary organic aerosols (SOAs) over the southern parts of China, whereas during the late fall and winter episodes, $\tau_{\text {MODIS }}$ and $\tau_{\text {CMAQ }}$ were higher due largely to high levels of $\mathrm{NH}_{4} \mathrm{NO}_{3}$ formed over the urban and industrial centers, as well as in areas with high $\mathrm{NH}_{3}$ emissions. $\tau_{\mathrm{CMAQ}}$ was in general larger than $\tau_{\text {MODIS }}$ during the year, except for spring. The high biases ( $\left.\tau_{\mathrm{CMAQ}}>\tau_{\mathrm{MODIS}}\right)$ may be due to the excessive formation of both $\left(\mathrm{NH}_{4}\right)_{2} \mathrm{SO}_{4}$ (summer episode) and $\mathrm{NH}_{4} \mathrm{NO}_{3}$ (fall and winter episodes) over China, possibly from the use of overestimated values for $\mathrm{NH}_{3}$ emissions in the CMAQ modeling. According to CMAQ modeling, particulate $\mathrm{NH}_{4} \mathrm{NO}_{3}$ made a $14 \%$ (summer) to $54 \%$ (winter) contribution to $\sigma_{\text {ext }}$ and $\tau_{\mathrm{CMAQ}}$. Therefore, the importance of $\mathrm{NH}_{4} \mathrm{NO}_{3}$ in estimating $\tau$ should not be ignored, particularly in studies of the East Asian air quality. In addition, the accuracy of $\tau_{\mathrm{M}-\mathrm{BAER}}$ and $\tau_{\mathrm{NASA}}$ was evaluated by a comparison with the AOD $\left(\tau_{\text {AERONET }}\right)$ from the AERONET sites in East Asia. Both $\tau_{\mathrm{M}-\mathrm{BAER}}$ and $\tau_{\mathrm{NASA}}$ showed a strong correlation with $\tau_{\mathrm{AERONET}}$ around the $1: 1$ line $(R=0.79)$, indicating promising potential for the application of both the M-BAER and NASA aerosol retrieval algorithms to satellite-based air quality monitoring studies in East Asia.

Published by Copernicus Publications on behalf of the European Geosciences Union. 


\section{Introduction}

Tropospheric aerosols are important components in the atmospheric system. They affect the global radiation budget directly by scattering or absorbing solar radiation and indirectly by changing cloud condensation nuclei $(\mathrm{CCN})$ concentrations and cloud lifetimes in the atmosphere (Twomey et al., 1984; Charlson et al., 1992; Kaufman et al., 2002; Ramanathan et al., 2007). Furthermore, tropospheric aerosols provide important surfaces for heterogeneous reactions between gas-phase air pollutants and atmospheric particles. Through the heterogeneous reactions, acidic and alkaline substances such as sulfate, nitrate, ammonium, and secondary organic aerosols (SOAs) are formed in the tropospheric aerosols, causing urban-, regional-, and global-scale air pollution (Jacobson, 1999; Ramanathan and Crutzen, 2003; Seinfeld et al., 2004).

The generation, transport, and formation of tropospheric aerosols and aerosol climatology (radiative effects) have often been studied by several collaborative research campaigns in East Asia, which integrate ground-based monitoring, aircraft and ship measurements, and 3-dimensional (3D) chemistry-transport modeling (CTM) efforts (e.g. PEMWest A and B, ACE-Asia, TRACE-P). However, such efforts have been limited by the inability of the point (groundbased) and line (aircraft- and ship-borne) measurements in the campaign activities to completely capture the spatially and temporally varying, regional-scale aerosol generation, formation, and transport characteristics.

For the last couple of decades, satellite-based, remotesensing techniques have been greatly developed. Particularly, environment observing satellites have provided 2-D, column-integrated aerosol "optical" concentrations as important complimentary and/or alternative data to the current point- and line-based "chemical" measurements (King et al., 1999; Singh and Jacob, 2000). The satellite-derived, aerosol optical properties have been applied to various research areas in air pollution studies such as: i) identifying the sources of air pollution (e.g. Herman et al., 1997), ii) estimating groundlevel particulate concentrations (e.g. Wang and Christopher, 2003; van Donkelaar et al., 2006), iii) understanding the long-range transport of air pollutants across oceans and continents (e.g. Husar et al., 2001; Colarco et al., 2002; Takemura et al., 2002; Lee et al., 2005b), iv) developing an advanced air quality forecast system (e.g. Al-Saadi et al., 2005), and v) aerosol climatology studies (e.g. Holben et al., 2001; Weaver et al., 2002; Kaufman et al., 2002; Hsu et al., 2003). Currently, many satellite platforms, such as Total Ozone Mapping Spectrometer (TOMS), Sea-Viewing Wide Fieldof-View Sensor (SeaWIFS), Moderate Resolution Imaging Spectroradiometer (MODIS), Medium Resolution Imaging Spectroradiometer (MERIS), Ozone Monitoring Instrument (OMI), Multi-angle Imaging Spectroradiometer (MISR), and Cloud-Aerosol Lidar and Infrared Pathfinder Satellite Observation (CALIPSO), have provided various qualities and lev- els of aerosol optical properties (King et al., 1999; Singh and Jacob, 2000; Kokhanovsky et al., 2006). Meanwhile, remotely sensed, aerosol optical column properties are also provided by ground-based, sunphotometer network and data archive, such as the Aerosol Robotics Network (AERONET) managed by the NASA Goddard Space Center (Holben et al., 1998). Therefore, it would be desirable and promising to use these abundant, satellite- and sunphotometer-derived aerosol optical properties in urban- and regional-scale air pollution studies, in conjunction with the point- and line-based chemical measurements and 3-D photochemical modeling. In this study, we therefore apply the satellite- and sunphotometerderived aerosol optical depth (hereafter, denoted as AOD or $\tau$ ) to particulate pollution studies over East Asia in the link with 3-D Eulerian CTM simulations. As the 3-D CTM, we used the US EPA Models-3/CMAQ v4.3 (Community Multiscale Air Quality) model. The AOD products retrieved from the MODIS instrument on board the NASA EOS/Terra satellite were used for the satellite-derived aerosol optical properties.

The integrated analysis of MODIS-, AERONET-, and Models-3/CMAQ-derived $\tau$ has many merits. First, while MODIS-derived AOD ( $\tau_{\text {MODIS }}$ ) can provide 2-D domainwide, aerosol distributions, it cannot provide information on the chemical composition of the atmospheric aerosols. This limitation can be overcome by using the 3-D CTM simulations. By conducting US EPA Models-3/CMAQ modeling in conjunction with the satellite-derived aerosol data, different aerosol formation characteristics in different regions and different seasons in East Asia can be more clearly described and identified. In addition, the integrated analysis of $\tau_{\text {MODIS }}$ and $\tau_{\text {CMAQ }}$ (CMAQ-predicted AOD) can allow a better understanding of the atmospheric/bio-geological chemical and physical processes occurring over East Asia. Secondly, the satellite-borne datasets typically have "temporal limitations", because satellite platforms take measurements over the area of interest (e.g. East Asia) only for limited times (e.g. 3-4 h). Such temporal limitations can be overcome using 3-D CTM simulations, because CTM simulations can provide 3-D results at all times over the episode period. Thirdly, the use of both $\tau_{\text {MODIS }}$ and $\tau_{\mathrm{CMAQ}}$ can overcome the "spatial limitations" that are typical in ground stations, ships, and aircraft measurements. For example, although sunphotometer measurements can provide "ground true values" of the aerosol optical properties, they are usually measured only at point stations. It is often difficult to represent the aerosol optical properties of surround areas using point measurements, particularly where the atmospheric concentrations are highly variable.

In this study, the MODIS platform was selected for four episodes that span from November 2001 to February 2003, because other platforms cannot fully cover the four episodes considered in this study or the MODIS platform provide better quality of aerosol products than the other instruments. Two combinations were tested over East Asia for the four 
episodes: (i) MODIS-MBAER algorithm (modified version of the Bremen aerosol retrieval algorithm) with the MODIS Level 1B data and (ii) MODIS-NASA Collection 5 (C005) algorithm (the MODIS Level 2 product). The former has largely been applied to European air quality studies (e.g. von Hoyningen et al., 2003; Kokhanovsky et al., 2006), and has begun to be applied to East Asian air quality studies only at a few locations of South Korea (Lee et al., 2005, 2007). In this study, the MODIS-MBAER combination is applied to the entire East Asian domain. The latter aerosol products have just recently begun to be released. Previously, the MODIS-NASA Collection 4 products were applied to East Asia (Chin et al., 2001, 2004) but the MODIS-NASA C005 has not been used in East Asian air quality studies. Thus, the use and comparison of both combinations in East Asian air quality studies is worthwhile.

This study carried out a comprehensive investigation by closely integrating the remote sensing data with the 3-D CTM products considering the detailed atmospheric gas/aerosol chemico-physical processes in the 3-D CMAQ modeling. This is a fundamental study to investigate the seasonally and regionally varying, aerosol formation and distribution characteristics in East Asia. Based on the results, we would like to establish a state-of-the-science chemical weather forecast system in East Asia in the near future, as in the USA (e.g. Al-Saadi et al., 2005), and to more accurately estimate the seasonally varying direct climate forcing by primary and secondary anthropogenic aerosols and mineral dust in East Asia.

\section{Model descriptions}

In order to conduct CTM over East Asia, we used a one-way coupling of PSU/NCAR MM5 (Pennsylvania State University/National Center for Atmospheric Research Mesoscale Model 5) to the US EPA Models-3/CMAQ model along with the East Asian emission inventory. The procedures are explained in detail below.

\subsection{US EPA Models-3/CMAQ modeling}

We performed 3-D Eulerian modeling over East Asia, using the US EPA Models-3/CMAQ v4.3 model (Byun and Ching, 1999; Byun and Schere, 2006). In this modeling study, both Carbon Bond Mechanism 4 (CBM4) and Carnegie-Mellon University (CMU) aqueous-phase chemistry were selected for the full consideration of gas-phase and aqueous-phase chemistries, respectively. For the advection and dry deposition of the gas and particulate species, the Piece-wise Parabolic Method (PPM) and latest version of Wesley scheme were chosen.

With regard to the aerosol chemical, dynamic, and thermodynamic processes, one of the most salient features of the US EPA Models-3/CMAQ v4.3 model is that the aerosol module includes the ISORROPIA aerosol equilibrium model and the mathematically-efficient, modal approach. The performance of the ISORROPIA model in predicting gas-particle distributions of ambient acidic (e.g. $\mathrm{H}_{2} \mathrm{SO}_{4}, \mathrm{HNO}_{3}, \mathrm{HCl}$ ) and alkaline (e.g. $\mathrm{NH}_{3}$ ) species is presented in Nenes et al. (1998). Capaldo et al. (2000) also reported that interactions between gas-phase species and fine-mode particles are sufficiently fast for this heterogeneous process to be dealt with in a thermodynamic manner. In contrast, interactions between gas-phase species and coarse-mode particles are so slow that this process must be treated in a kinetic or dynamic manner, in a method called the "CMU hybrid approach". The aerosol modal approach has been applied to 3-D photochemical models because it can provide mathematically-convenient forms of formulas describing time-varying particle growth due to aerosol dynamic processes, such as coagulation and condensation (Binkowski, 1999; Binkowski and Roselle, 2003). Unlike the other 3-D aerosol modeling studies (e.g. Takemura et al., 2002; Chin et al., 2004), the species-wise size distributions were not fixed in this study due to the advantage of the modal approach.

The study domain covered approximately the region from $100^{\circ}$ to $150^{\circ} \mathrm{E}$ and from $20^{\circ}$ to $50^{\circ} \mathrm{N}$ (shown in Fig. 1), which includes all of Korea, Japan, most of eastern China, and parts of Mongolia and Russia. The region has dramatic variations in topography and land type, and features mixtures of industrial/commercial/urban centers and agricultural/rural regions. Figure 1 illustrates the Chinese urban-industrial centers, such as Bohai Bay, Sichuan Basin, and Yangtze Delta areas, denoted as regions $\mathrm{A}, \mathrm{B}$ and $\mathrm{C}$, respectively, and the region with high $\mathrm{NH}_{3}$ emission due to strong agricultural and livestock farming activities (Hebei, Shandong, Henan, Jiangsu, and Anhui provinces). In addition, dust storms frequently erupt from the Gobi desert, loess plateau, and Inner Mongolia, typically in spring.

In the 3-D CMAQ modeling, the horizontal grid spacing was $108 \mathrm{~km} \times 108 \mathrm{~km}$ with 46 and 33 grids in the $\mathrm{x}$ and y-directions, respectively, and vertical domain ranged from $1000 \mathrm{hPa}$ to $180 \mathrm{hPa}$, with 24 terrains following $\sigma$ coordinates, giving a total of 36432 grid points.

The 3-D photochemical modeling was conducted for four episodes, representing the four seasons, in East Asia. The periods of the four episodes, each approximately 3 weeks long, were: i) 9-27 November 2001 (Late Fall); ii) 25 March-13 April 2002 (Spring); iii) 24 August-13 September 2002 (Late Summer); and iv) 11-28 February 2003 (Winter). US EPA Models-3/CMAQ modeling was conducted for the four episodes using the MET fields generated from the PSU/NCAR MM5 modeling.

\subsection{Meteorological modeling}

As a meteorological preprocessor for the US EPA Models3/CMAQ CTM, PSU/NCAR MM5 was used in this study. In the meteorological modeling (MET modeling), 


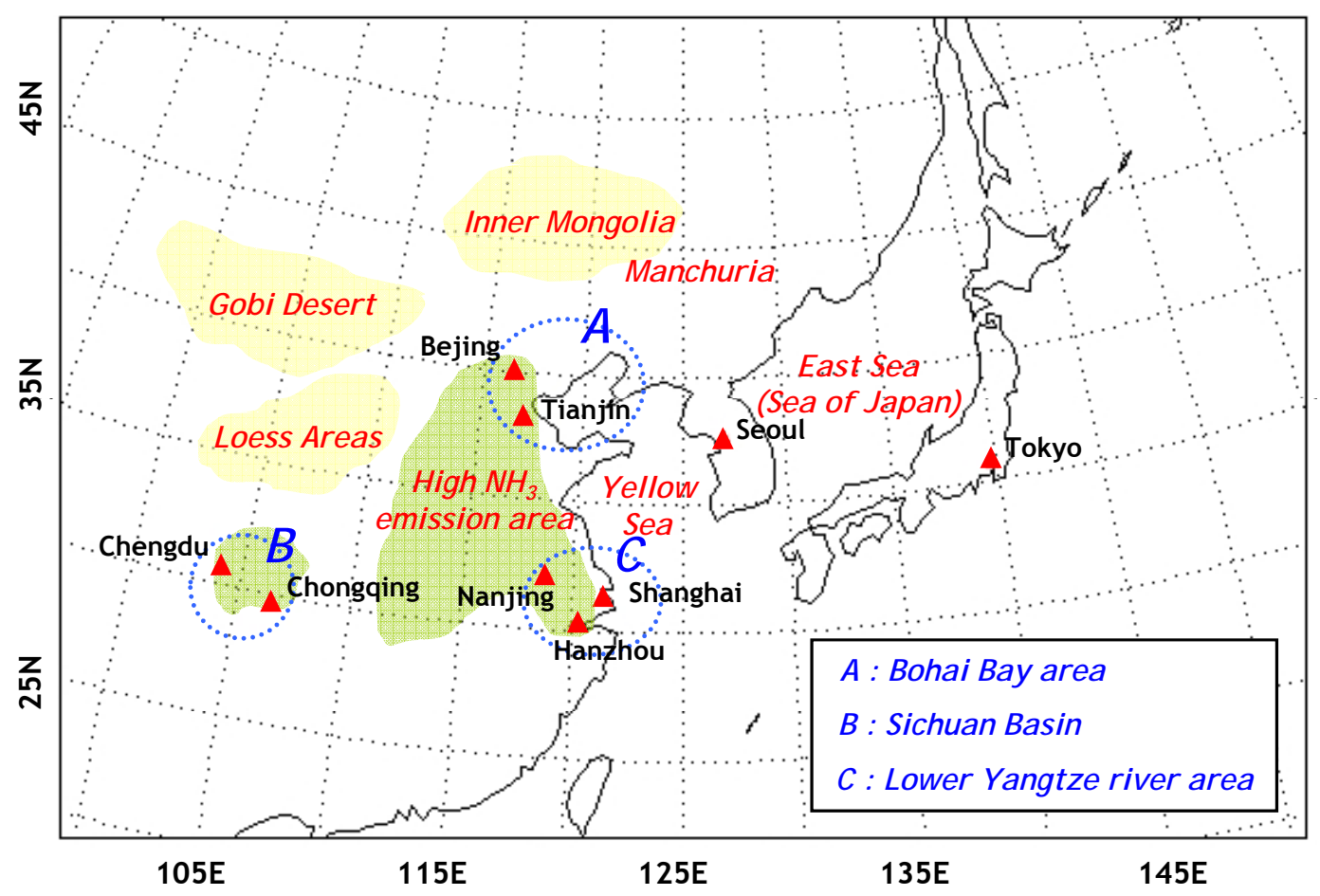

Fig. 1. Modeling domain in this study.

the 3-D non-hydrostatic primitive equation was selected as the governing equation. The horizontal spacing was $108 \mathrm{~km} \times 108 \mathrm{~km}$, which follows the horizontal spacing of the US EPA Models-3/CMAQ model. However, the size of the domain for MM5 modeling was larger by two grids than that for US EPA Models-3/CMAQ modeling in the 4 compass directions in order to minimize the uncertainties that could occur when meteorological boundary conditions were set for US EPA Models-3/CMAQ modeling. For the same reason, the vertical domain for MET modeling was also higher, from 1000 to $70 \mathrm{hPa}$, than that for US EPA Models-3/CMAQ modeling, with 30 terrain following $\sigma$ coordinates. For the MET modeling, $2.5^{\circ} \times 2.5^{\circ}$ re-analyzed, National Centers for Environmental Prediction (re-analyzed NCEP) data were used to drive MM5. The reanalyzed NCEP data used in this study also contained the sea surface temperature (SST) data. In addition, the data included in the PSU/NCAR storage were used to give consideration for the terrain heights within the domain. In order to improve the accuracy of the MET fields, NCEP Automated Data Processing (ADP) global surface and upper air observation data were utilized by employing Four-D Data Assimilation (FDDA) techniques with nudging coefficients of $2.5 \times 10^{-4}$ for temperature and wind and of $1 \times 10^{-5}$ for mixing ratios (Stauffer and Seaman, 1990, 1994). In the MM5 modeling, Blackadar scheme and five-layer land surface models (LSMs) were used for the planetary boundary layer (PBL) parameterization and associated ground temperature scheme, respectively.
Rapid Radiative Transfer Model (RRTM), Grell scheme, and Reisner-2 scheme were chosen to give consideration for atmospheric radiation, cumulus parameterization, and cloud microphysics, respectively (Grell et al., 1994; Reisner et al., 1998). Using these schemes, grided MET fields were generated with a high temporal resolution of " 1 -h interval". After the generation of the grided MET fields from the MM5 modeling, the data were then processed and converted by the meteorological-chemistry interface processor (MCIP) to produce MET inputs for the US EPA Models-3/CMAQ model.

\subsection{Emissions}

Resolved emission data at $1^{\circ} \times 1^{\circ}$ were obtained from the ACE-ASIA (Asian Pacific Regional Aerosol Characterization) emission estimation web site (http://www.cgrer.uiowa. edu/EMISSION_DATA_new/index_16.html). The emission data for $\mathrm{NO}_{\mathrm{x}}$ and $\mathrm{SO}_{2}$ were of primary importance, as they are the precursors of particulate nitrate and sulfate, respectively. The emission inventory for the two primary pollutant species in East Asia has been continuously improved and evaluated in the literature (van Aardenne et al., 1999; Streets et al., 2003; Woo et al., 2003). It is generally believed that the uncertainties in their emissions are relatively small. Uncertainty levels of \pm 37 and $\pm 16 \%$ were reported by Streets et al. (2003) for $\mathrm{NO}_{\mathrm{x}}$ and $\mathrm{SO}_{2}$ emissions, respectively, in East Asia. In contrast, $\mathrm{NH}_{3}$ emission in East Asia is more uncertain and poorly-understood, despite being 
an important gas-phase precursor of particulate ammonium. The $\mathrm{NH}_{3}$ emission used in this study was estimated by taking four major sources into account: i) fertilizer applications, ii) livestock-farming (animal excreta and manures), iii) biomass/bio-fuel burnings, and iv) industrial combustion (Woo et al., 2003). According to Kim et al. (2006), the use of the ACE-ASIA $\mathrm{NH}_{3}$ emission inventory in the CTM simulations over East Asia resulted in over-predictions of the particulate $\mathrm{NH}_{4} \mathrm{NO}_{3}$ concentrations, which strongly suggests that the $\mathrm{NH}_{3}$ emissions of the official ACE-ASIA inventory are overestimated. This issue will be further discussed in Sect. 4.1.4.

Non-Methane Volatile Organic Compound (NMVOC) emissions are also important, since they are SOA precursors. In this study, we conducted chemical speciation (chemical species splitting) of the total NMVOC emissions in East Asia, using the SPECIATE database built up by US EPA. For the considerations of the biogenic isoprene and monoterpene emissions, we used the monthly emission data from the Global Emission Inventory Activity (http://www.geiacenter. org). Emissions of primary carbonaceous particles (black carbon and organic carbon: BC and OC) were also included in the emission inventory. Some of the aforementioned emissions are shown in Fig. 2.

Spring is a typical dust season in East Asia. During the spring episode studied, high wind speeds over the Gobi desert resulted in significant dust emissions. In order to estimate the mass flux of dust emissions ( $\left.E_{\text {Dust }}\right)$, a method that employs both friction velocity $\left(u_{*}\right)$ and threshold friction velocity $\left(u_{* t}\right)$ was utilized (Gillette and Passi, 1988; Gillette et al., 1992):

$E_{\text {Dust }}=C\left[u_{*}^{4}\left(1-\frac{u_{*, t}}{u_{*}}\right)\right]$

where $C$ is a combined constant. This parameterization was successfully tested by several previous studies over the same East Asian domain (Phadnis and Carmichael, 2000; Song and Carmichael, 2001a, b). Unfortunately, however, the seasalt particle (another important natural aerosol) generation over the ocean areas of the domain was not considered in this study, partly because the primary study focus was on the modeling investigations for anthropogenic-influenced pollution areas. This consideration should, however, be included in future study.

\section{Remote sensing of aerosol optical properties}

In this study, we used two different types of satellite-derived, aerosol optical properties: Aerosol Index (AI) and AOD. AI was retrieved from the Earth Probe TOMS platform and AOD from the NASA/Terra MODIS satellite sensor. The AOD values at several ground locations inside the domain were also obtained through a sunphotometer network of AERONET managed by the NASA Goddard Space Flight
Center (Holben et al., 1998). These aerosol optical properties were then applied to further analysis in conjunction with 3-D Eulerian MM5-CMAQ modeling.

\subsection{TOMS aerosol index}

TOMS instruments (McPeters et al., 1996) have been providing useful global UV radiation, ozone, and UV absorbing aerosol data for more than two decades. The TOMS AI was initially computed for the correction of aerosol-induced errors in the retrieval of total ozone (Herman et al. 1997; Torres and Bhartia, 1999). The TOMS AI is calculated on the basis of the difference between the measured spectral contrast of the $360 \mathrm{~nm}$ and $331 \mathrm{~nm}$ wavelength radiances and the contrast calculated from the radiative transfer theory for a pure molecular atmosphere, which allows for the detection of UV absorbing aerosols over both land and ocean. In the current version 8 Nimbus7 TOMS (1979-1993), Earth Probe TOMS (1996-2007) and version 2 Aura OMI (2004-present) algorithms, it is mathematically defined as:

$\mathrm{AI}=100\left\{\log _{10}\left(\frac{I_{360}}{I_{331}}\right)_{\text {meas }}-\log _{10}\left(\frac{I_{360}}{I_{331}}\right)_{\text {calc }}\right\}$

where the indices "meas" and "calc" indicate the radiance measured by TOMS and the radiance calculated for pure Rayleigh scattering, respectively. AI is positive for absorbing aerosols (e.g. dust and BC particles) and negative for nonabsorbing aerosols (e.g. sulfates). In this study, the TOMS AI data were retrieved from the Earth Probe TOMS platform.

\subsection{MODIS-derived AOD}

The MODIS instrument is mounted on two NASA Earth Observation System (EOS) platforms: the Terra and Aqua satellites. The former is on a descending orbit flying southward across the equator around 10:30 local sun time, while the latter Aqua satellite is on an ascending orbit flying northward around 13:30 local sun time. MODIS has 36 channels ranging from $0.41 \mu \mathrm{m}$ to $14 \mu \mathrm{m}$ at three different spatial resolutions $(250 \mathrm{~m}, 500 \mathrm{~m}$ and $1 \mathrm{~km})$. In this study, we used the AOD retrieved from the EOS/Terra MODIS platform.

For spatially-resolved aerosol retrieval from MODIS data, a modified version of the BAER algorithm (Lee et al., 2005, 2006a, 2007) was applied. To avoid inhibition from cloud and sun-glint effects, the MODIS L1B data were first processed to filter out cloud and sun glint pixels (Ackerman et al., 1998; Martins et al., 2002), after which the following radiative transfer equation was used to calculate the aerosol reflectance $\left(\rho_{\mathrm{AERO}}\right)$ :

$\rho_{\mathrm{AERO}}(\lambda)=\rho_{\mathrm{TOA}}(\lambda)-\rho_{\text {Ray }}(\lambda)-\frac{T_{0} \cdot T_{S} \cdot \rho_{\text {Surf }}}{1-s \cdot \rho_{\text {Surf }}}$

where $\rho_{\mathrm{TOA}}, \rho_{\text {Ray }}$, and $\rho_{\text {Surf }}$ represent the Top-of-theAtmosphere (TOA) reflectance, Rayleigh path radiance, and 

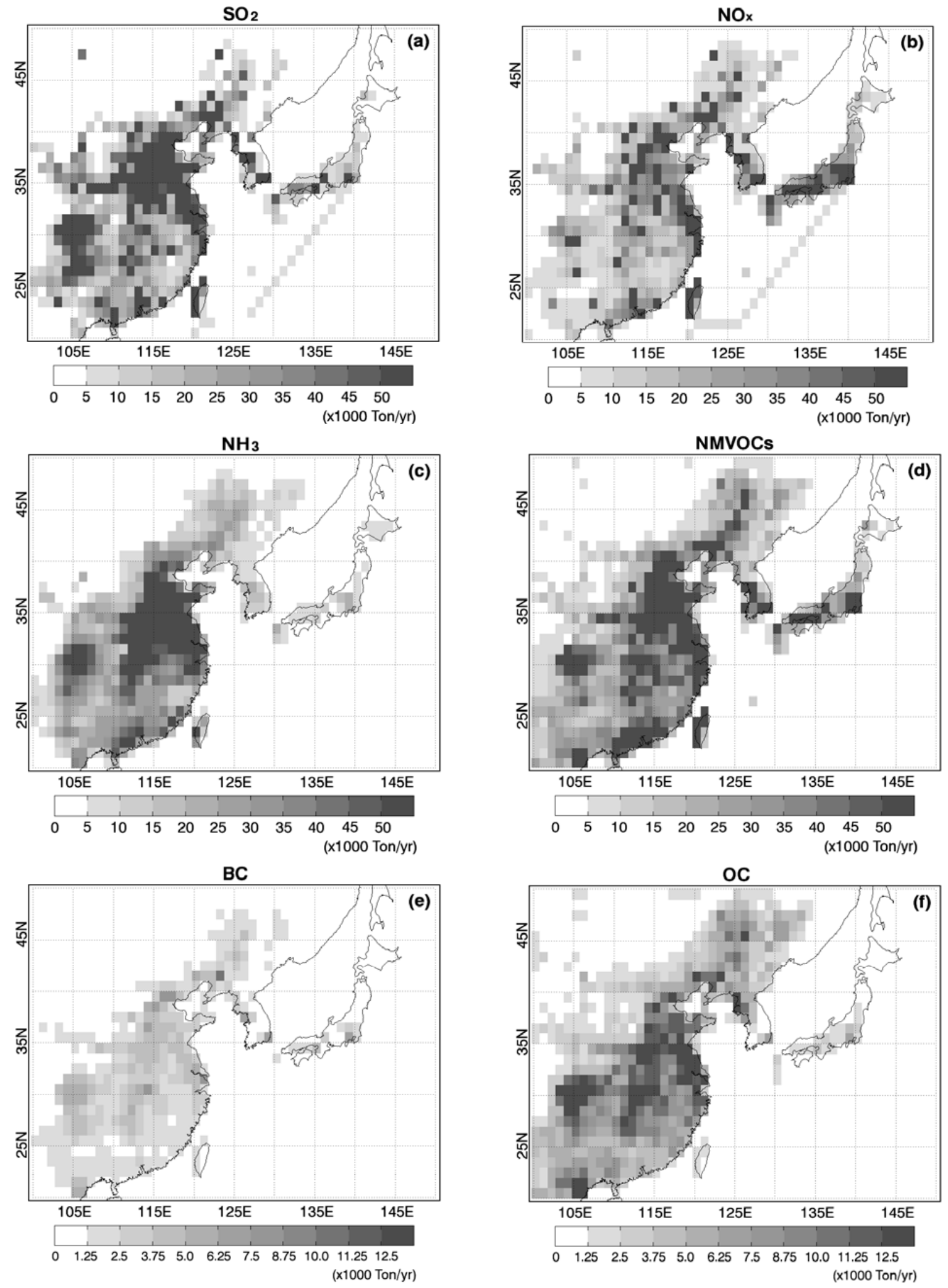

Fig. 2. Emissions in East Asia: (a) $\mathrm{SO}_{2}$, (b) $\mathrm{NO}_{\mathrm{x}}$, (c) $\mathrm{NH}_{3}$, (d) NMVOCs, (e) $\mathrm{BC}$, and (f) $\mathrm{OC}$. 


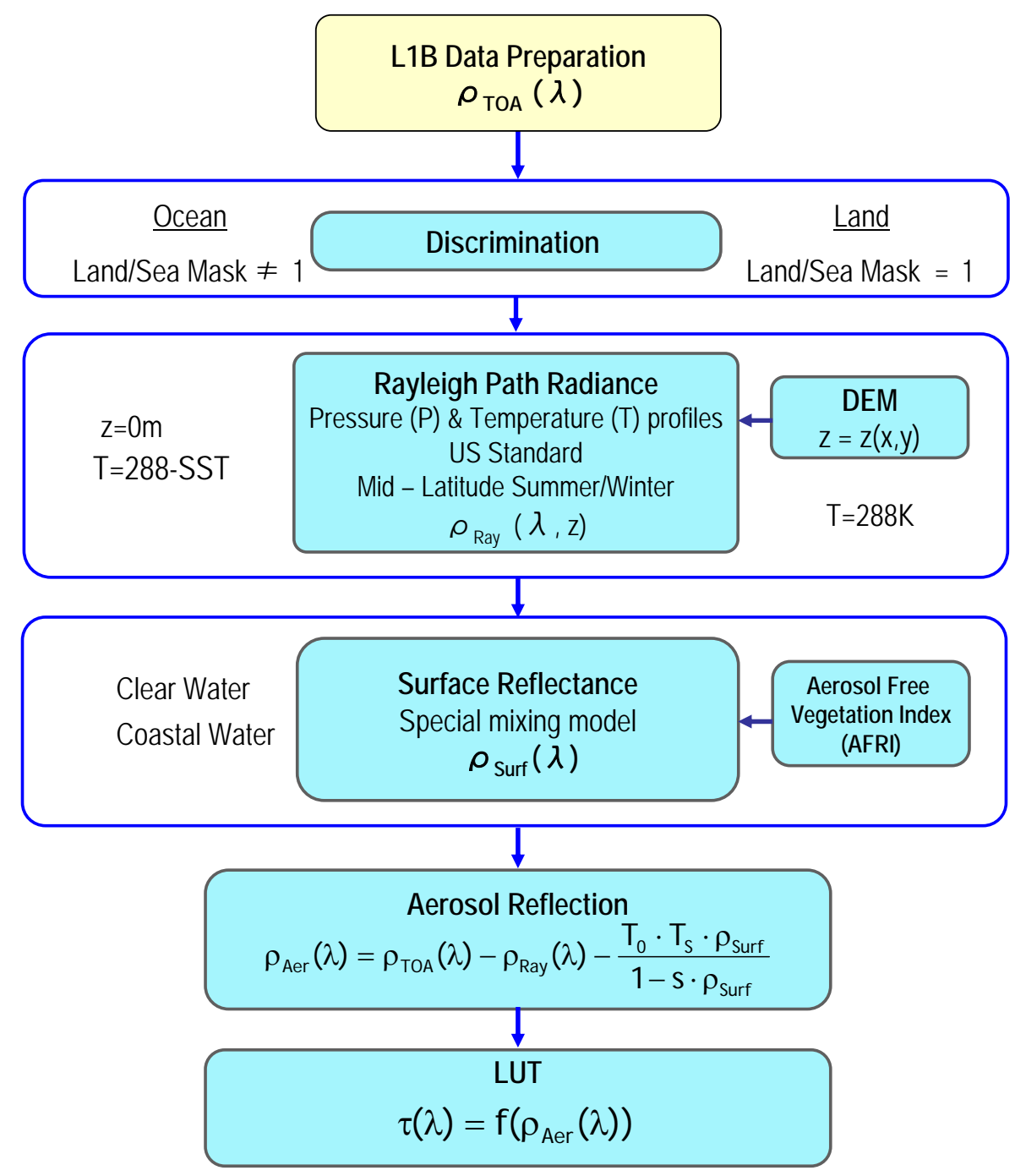

Fig. 3. MODIS AOD retrieval through the M-BAER algorithm. DEM, SST, and LUT represent the digital elevation model, sea surface temperature, and look-up table, respectively.

surface reflectance, respectively, $T_{o}$ and $T_{S}$ the total and surface transmittance, respectively, and $s$ the hemispheric reflectance. As shown in Fig. 3 and Eq. (3), the M-BAER algorithm is composed of three parts. First, MODIS TOA reflectance in a cloud-free pixel is separated from Rayleigh path radiance. The Rayleigh path radiance can be determined from the altitude-dependent surface pressure $p(z)$ in each pixel (Bucholtz, 1995). Second, the surface reflectance obtained from the "linear mixing model" is separated (shown in Eq. (4) below). Finally, AOD can be determined by the pre-calculated look-up tables (LUT) approach.

The NASA operational MODIS Level 2 aerosol products (MOD04 for Terra, MYD04 for Aqua) also provide a daily estimation of the $10 \mathrm{~km}$-resolved aerosol optical properties over the globe. The estimated uncertainty of the MODIS AOD product was reported to be $\pm 0.05 \pm 0.15 \tau$ over land
Table 1. Parameters of the best-fit Eq. (6) relating $f(\mathrm{RH})$ to relative humidity $(\mathrm{RH})$ in the four seasons.

\begin{tabular}{lrrr}
\hline & $b_{0}$ & $b_{1}$ & $b_{2}$ \\
\hline Spring & -0.01097 & 0.78095 & 0.08015 \\
Summer & -0.18614 & 0.99211 & - \\
Fall & -0.24812 & 1.01865 & 0.01074 \\
Winter & 0.34603 & 0.81984 & - \\
Annual & 0.33713 & 0.58601 & 0.09164 \\
\hline
\end{tabular}

and $0.03 \pm 0.05 \tau$ over the ocean (Remer et al., 2005). Recently, the NASA MODIS aerosol retrieval algorithm has been improved, and is starting to produce new products denoted as C005 (Remer et al., 2005; Levy et al., 2007). 
Table 2. Comparison of the M-BAER and MODIS C005 aerosol retrieval algorithms.

\begin{tabular}{|c|c|c|}
\hline & M-BAER & MODIS (C005) \\
\hline \multirow[t]{2}{*}{ References } & Von Hoyningen et al. (2003) & Remer et al. (2006) \\
\hline & Lee et al. $(2004,2007)$ & Levy et al. (2007) \\
\hline \multirow[t]{3}{*}{ Clear sky flag } & $\begin{array}{l}\text { Cloud mask (Ackerman et al., 1998; Martin et al., } \\
\text { 2002), }\end{array}$ & $\begin{array}{l}\text { Cloud mask(Ackerman et al., 1998; Martin et al., } \\
\text { 2002), }\end{array}$ \\
\hline & Snow/ice mask (Li et al., 2005), & Snow/ice mask (Li et al., 2005), \\
\hline & Ocean sediment mask (Li et al., 2002) & Ocean sediment mask (Li et al., 2002) \\
\hline \multirow[t]{2}{*}{ Surface reflectance } & Ocean: Ocean water BRDF & Ocean: Ocean water BRDF \\
\hline & $\begin{array}{l}\text { Land: Spectral mixing of vegetation and bare soil } \\
\text { spectra. }\end{array}$ & Land: Spectral conversion from $\rho_{\mathrm{TOA}}(2.1 \mu \mathrm{m})$ \\
\hline Aerosol model & OPAC data base (Hess et al., 1998) & $\begin{array}{l}\text { Global aerosol climatology model; } \\
\text { Ocean ( } 4 \text { small, } 5 \text { large) and } \\
\text { Land (5) }\end{array}$ \\
\hline Determination of AOD & $\begin{array}{l}\text { Spectral smooth (e.g. find the minimum } x^{2} \text { ), } \\
x^{2}=\frac{1}{n} \sum_{i=1}^{n}\left(\frac{\rho_{\mathrm{aer}}^{m}-\rho_{\mathrm{aer}}^{\mathrm{LUT}}}{\rho_{\mathrm{aer}}^{m}}\right)^{2}\end{array}$ & $\begin{array}{l}\text { Mixture of fine and coarse mode (e.g. find the best } \\
\eta \text { minimizing } \varepsilon \text { ) } \\
\rho_{\mathrm{aer}}^{\mathrm{LUT}}=\eta \rho_{\mathrm{aer}}^{\text {fine }}+(1-\eta) \rho_{\mathrm{aer}}^{\text {coarse }}\end{array}$ \\
\hline \multirow[t]{2}{*}{ Wavelengths } & Land $(0.47,0.55,0.66,2.13 \mu \mathrm{m})$ & Land $(0.47,0.55,0.66,2.13 \mu \mathrm{m})$ \\
\hline & $\begin{array}{l}\text { Ocean }(0.47, \quad 0.55, \quad 0.66, \quad 0.86, \quad 1.24,1.64 \text {, } \\
2.13 \mu \mathrm{m})\end{array}$ & $\begin{array}{l}\text { Ocean }(0.47,0.55,0.66,0.86, \quad 1.24,1.64, \\
2.13 \mu \mathrm{m})\end{array}$ \\
\hline Spatial resolution & $<1 \mathrm{~km}$ & $10 \mathrm{~km}$ \\
\hline
\end{tabular}

In the recent NASA C005 algorithm, several assumptions, including aerosol models, the VIS/SWIR surface reflectance parameterization and the statistical implications of deriving below-zero AOD, have been updated. More detailed discussions can be found in the Algorithm Theoretical Basis Document (ATBD, http://modis.gsfc.nasa.gov/data/atbd/ atbd_mod02.pdf).

The M-BAER and the NASA C005 aerosol retrieval algorithms use similar pre-processes to prepare clear-sky pixels for aerosol retrieval. Both algorithms use cloud mask (Ackerman et al., 1998; Martin et al., 2002), snow/ice mask (Li et al., 2005), and ocean sediment mask (Li et al., 2002). Although the aerosol retrieval steps with clear-sky pixels are different, the final objective of the numerical procedures is to find aerosol properties by comparing the measured and precalculated values. Table 2 lists the major characteristics of the two algorithms. The most important difference is found in the correction of surface reflectance. The NASA C005 algorithm uses "spectral conversion", based on the VIS/SWIR

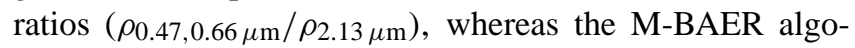
rithm uses "spectral linear mixing", which is a reflectance mixture tuned by the vegetation index between "green vegetation"" and "BAER soil". The spectral linear mixing is expressed as:
$\rho_{\mathrm{Surf}}(\lambda)=C_{\mathrm{Veg}} \rho_{\mathrm{Veg}}(\lambda)+\left(1-C_{\mathrm{Veg}}\right) \rho_{\mathrm{Soil}}(\lambda)$

where $\rho_{\mathrm{Veg}}(\lambda)$ and $\rho_{\text {Soil }}(\lambda)$ are the spectral reflectance of "green vegetation" and "BAER soil", respectively, and $C_{\text {Veg }}$ is the vegetation fraction, which is the aerosol free vegetation index (AFRI) in each pixel (Karnieli et al., 2001). Although the spectral conversion ratios in the NASA C005 are quite dependent on land surface and cover types, their assessments of accuracy are reported to be reasonable for dark pixel (Kaufman et al., 1998; Levy et al., 2007). In addition, each algorithm has its own method for determining the AOD with a specific aerosol model. The M-BAER algorithm uses the aerosol optical database from the OPAC (Hess et al., 1998) for a LUT construction for a $1 \mathrm{~km}$ spatial resolution. This method can determine the most suitable aerosol model in a given pixel within a regional/local scale. Minimizing the error term $\left(\chi^{2}\right)$ describes the agreement between the measured and calculated aerosol reflection. However, the case of the NASA C005 is more complicated. The LUTs are created from 4 fine- and 5 coarse-modes for over-ocean, and 5 modes for over-land (Remer et al., 2006). For the AOD determination, the best aerosol model from the bi-lognormal distribution with a choice of fine- and coarse-modes was selected by minimizing the error $(\varepsilon)$ in Table 2. 
Lee et al. (2006a, b, 2007) have applied the M-BAER algorithm to the retrieval of $\tau$ from the NASA EOS/Terra MODIS platform. They then evaluated the performance of the M-BAER algorithm over "South Korea" by comparing $\tau_{\text {M-BAER }}$ with $\tau_{\text {AERONET }}$. They found that the M-BAER algorithm worked very well, showing good agreement between $\tau_{\mathrm{M} \text {-BAER }}$ and $\tau_{\text {AERONET }}$ (e.g. $R=0.9$ and linear slop $=0.89$ were reported by Lee et al., 2007). As mentioned earlier, this study is an extension of their works into "East Asia" in regard to satellite-derived aerosol optical property monitoring. In addition, this study compared two aerosol products ( $\tau_{\mathrm{M}-\mathrm{BAER}}$ and $\left.\tau_{\mathrm{NASA}}\right)$, and evaluate the accuracy of both the satellite-derived AOD with $\tau_{\mathrm{CMAQ}}$ and $\tau_{\mathrm{AERONET}}$ in East Asia.

\subsection{CMAQ-derived AOD}

Section 3.2 presented the method to retrieve $\tau_{\text {MODIS }}$ from the NASA EOS/Terra MODIS platform via the M-BAER and NASA C005 algorithms. This section introduces methods to estimate $\tau_{\mathrm{CMAQ}}$ from the particulate concentrations generated from the US EPA Models-3/CMAQ model. AOD $(\tau)$ is theoretically calculated by integrating the aerosol extinction coefficient $\left(\sigma_{\text {ext }}(z)\right)$ with respect to altitudes $(z)$, i.e.:

$\tau=\int \sigma_{\mathrm{ext}}(z) \cdot d z$

The method by which $\sigma_{\text {ext }}(z)$ is calculated from the particulate composition is therefore important. Actually, there are two such methods. The first is based on the Mie theory, in which the extinction coefficient of a certain species $i\left(\sigma_{\text {ext }, \mathrm{i}}\right)$ is calculated as a function of density of particulate species $i$ $\left(\rho_{i}\right)$, mass of particulate species $i$ at an altitude $z\left(M_{i}(z)\right)$, extinction efficiency of particulate species $i\left(Q_{\text {ext, }}\right)$, and effective radius of particulate species $i\left(r_{\mathrm{eff}, \mathrm{i}}(z)\right)$ (d'Almeida et al., 1991; Chin et al., 2002):

$\sigma_{\mathrm{ext}, \mathrm{i}}(z)=\frac{3 Q_{\mathrm{ext}, \mathrm{i}} M_{i}(z)}{4 \rho_{i} r_{\mathrm{eff}, \mathrm{i}}(z)}$

The total aerosol extinction coefficient $\left(\sigma_{\text {ext }}\right)$ is then calculated by $\sigma_{\mathrm{ext}}=\sum_{i} \sigma_{\mathrm{ext}, \mathrm{i}}$, based on the assumption that all the particulate species, except for particulate water, are externally mixed. Of the aerosol properties in Eq. (6), $r_{\mathrm{eff}, \mathrm{i}}(z)$ is a function of the size-distribution of particulate species $i$ and altitude $z$, and $Q_{\text {ext,i }}$ is a function of $r_{\text {eff,i }}$, refractive index $\left(m_{i}\right)$ of particulate species $i$, and wavelength $(\lambda)$, i.e. $Q_{\text {ext,i }}$ $\left(r_{\text {eff }}, m_{i}, \lambda\right)$. Also, $\rho_{i}, Q_{\text {ext,i }}$, and $r_{\text {eff,i }}$ are strongly variable with ambient relative humidity (RH), since each particulate species has different hygroscopic capability. Thus, all the aerosol properties in Eq. (6) are dependent on RH (d'Almeida et al., 1991; Chin et al., 2002, and more references therein). The Mie-theory-based, extinction coefficient calculations are, therefore, based on several assumptions, as presented by Chin et al. (2002, 2004). For example, in Chin et al's global 3-D modeling studies (2002, 2004), the sizedistribution of each particulate species was assumed (or determined), and then fixed during the 3-D model simulations. However, for example, the size-distributions of dust particles have high spatial and temporal variations due to their different emission strength and deposition characteristics, and sulfate and SOA distributions are also spatially and temporally variable due to different particle growth rates. In addition, the changes of the aerosol properties due to hygroscopicity are highly uncertain. In East Asia, the consideration of $\mathrm{NH}_{4} \mathrm{NO}_{3}$ is of primary importance, but its sizedistribution has not been sufficiently characterized to enable the use of the Mie-theory-based extinction coefficient calculations. Therefore, following consideration of these uncertainties we estimated $\sigma_{\text {ext }}$ with an empirical correlation, often called the "reconstructed extinction coefficient method". The method was first proposed by Malm et al. (1994) to investigate the spatial and temporal variability of haze and visibility impairment in USA, and has been continuously improved by several researchers (e.g. Malm and Kreidenweis, 1997; Malm, 2000). Among the correlations available, we adopt the latest version of the formula proposed by Malm (2000) as a part of the Integracy Monitoring of Projected Visual environment (IMPROVE) program:

$$
\begin{aligned}
\sigma_{\text {ext }}\left(M^{-1}\right)= & 3.0 \times f(\mathrm{RH}) \times\left\{\left[\left(\mathrm{NH}_{4}\right)_{2} \mathrm{SO}_{4}\right]+\left[\mathrm{NH}_{4} \mathrm{NO}_{3}\right]\right\} \\
& +4.0 \times[\mathrm{SOAs}] \\
& +10.0 \times[\mathrm{BC}]+1.0 \times[\text { fine-dust }]+0.6 \\
& \times[\text { coarse-dust }]
\end{aligned}
$$

The numbers in the front of each species are the optimized specific (or dry mass) extinction efficiency $\left(\mathrm{m}^{2} \mathrm{~g}^{-1}\right)$. Estimates of the total ambient $\sigma_{\mathrm{ext}}\left(\mathrm{Mm}^{-1}\right)$ correspond to $\lambda=550 \mathrm{~nm}$. The assumption made in using Eq. (7) was that the aerosol characteristics in East Asia are the same as those in USA. However, the specific extinction efficiencies of SOAs and dust particles can be affected by the SOA constituents and the dust mineralogy. The SOA speciation depends strongly on the anthropogenic NMVOC emission characteristics and the activity of biogenic emissions inside the study domain. In the case of dust particles, the fraction of $\alpha$ $\mathrm{Fe}_{2} \mathrm{O}_{3}$, which is a light absorption component in dust particles, is an important parameter with significant regional variations. This method is also based on the same assumption as the Mie-theory-based method, i.e., all the particulate species, except for particulate water, are externally mixed. As shown in Eq. (7), $\sigma_{\text {ext }}$ is conveniently calculated from the particulate concentrations (in $\mu \mathrm{g} \mathrm{m}^{-3}$ ) of $\left(\mathrm{NH}_{4}\right)_{2} \mathrm{SO}_{4}, \mathrm{NH}_{4} \mathrm{NO}_{3}$, $\mathrm{BC}$, SOAs, and fine-mode and coarse-mode dust, which are generated from the US EPA Models-3/CMAQ model. In Eq. (7), the variability in $\sigma_{\text {ext }}$ caused by variable RH was considered by hygroscopic growth factor or extinction enhancement factor, $f(\mathrm{RH})$. In the calculations, only $\left(\mathrm{NH}_{4}\right)_{2} \mathrm{SO}_{4}$ and $\mathrm{NH}_{4} \mathrm{NO}_{3}$ were considered hygroscopic. The consideration of $f(\mathrm{RH})$ is of primary importance, since $\sigma_{\mathrm{ext}}$ varies greatly with 
$\mathrm{RH}$, particularly when $\mathrm{RH}$ is larger than $80 \%$. $f(\mathrm{RH})$ was calculated assuming a log-normal distribution with a geometric mean diameter $\left(D_{g}\right)$ of $0.4 \mu \mathrm{m}$ and geometric standard deviation $\left(\sigma_{g}\right)$ of 2 . These values are also consistent with the size-distributions observed during the ACE-Asia campaign in East Asia (Conant et al., 2003). In addition, $f(\mathrm{RH})$ exhibits seasonal variation which is accounted for by using the following equation:

$$
f(\mathrm{RH})=b_{0}+b_{1}\left(\frac{1}{1-\mathrm{RH}}\right)+b_{2}\left(\frac{1}{1-\mathrm{RH}}\right)^{2}
$$

The correlation parameters $\left(b_{0}, b_{1}\right.$, and $\left.b_{2}\right)$ in Eq. (8) for the different seasons are presented in Table 1. Here, a further assumption made in using Eq. (8) is that the aerosol hygroscopic characteristics in East Asia are the same as those in USA. In addition, for the calculations of $\mathrm{RH}\left(\equiv e(z) / e_{w}(z)\right)$, water vapor pressure $(e(z))$ is calculated by the equation proposed by Mattis et al. (2002) and saturation vapor pressure is estimated by the Bolton equation shown below:

$e_{w}(z)=6.112 \times \exp \left(17.67 \times \frac{T-273.15}{T-29.65}\right)$

where $T$ is temperature in $\mathrm{K}$ and $e_{w}(z)$ indicates the saturation vapor pressure at an altitude $z$. As discussed by Conant et al. (2003), the mass extinction efficiencies are relatively insensitive to the size-distribution of secondary particulate species in East Asia because the Angstrom exponent $(\alpha)$ of the polluted East Asia plumes is typically close to unity. One exception is dust particles. The mass extinction efficiencies of dust particles are size-dependent. Therefore, this study considered two modes of dust particles: fine- and coarsemode dust particles (refer to Eq. 7).

\subsection{AERONET data}

Two sunphotometer/skyradiometer networks have been operated in East Asia: AERONET and SKYNET (Skyradiometer Network). The former is a federated sunphotometer network and data archive for aerosol characterization that has been managed by the NASA Goddard Space Flight Center in USA (Holben et al., 1998). The latter is a skyradiometer (an instrument similar to sunphotometer) network established in late 1997 for studying the role of aerosols in climate change as a part of GEWEX Asian Monsoon Experiment/Asian Automatic Weather Station Network (GAME/AAN) (Kim et al., 2004). In this study, we obtained the sunphotometer-derived $\operatorname{AOD}\left(\tau_{\text {AERONET }}\right)$ from AERONET.

AERONET has 22 ground-based monitoring stations within our East Asian modeling domain (shown in Fig. 10), and provides total column spectral $\tau$, single scattering albedo $\left(\omega_{o}\right)$, and reflective index at visible and NIR wavelengths. Among the aerosol properties, the spectral $\tau$ provided by AERONET are regarded as "ground true values", since they are unaffected by surface reflectance, unlike the satellitederived $\tau$. In this study, we selected $\tau$ at $550 \mathrm{~nm}$, by using a power law interpolation. For example, at the Gosan
AERONET site the AOD values at $550 \mathrm{~nm}$ were interpolated between $\tau$ at $440 \mathrm{~nm}$ and $675 \mathrm{~nm}$. In addition, the sunphotometer data closest to the satellite scanning time were taken from the AERONET sites and $\tau_{\text {MODIS }}$ were selected at the nearest locations to the AERONET sites for further comparison studies.

\section{Results and discussions}

Spatial, temporal, and seasonal distributions of aerosol mass loading and $\tau$ generated by US EPA Models-3/CMAQ modeling were compared with MODIS-derived AOD and AOD from AERONET over East Asia. Following these comparisons, we discuss the species-wise formation characteristics of particulate pollutants in the different regions of East Asia for the four seasons.

\subsection{CMAQ- and MODIS-derived AOD in East Asia}

\subsubsection{CMAQ-derived AOD vs. MODIS-derived AOD}

The two MODIS-derived AOD ( $\tau_{\mathrm{M}-\mathrm{BAER}}$ and $\left.\tau_{\mathrm{NASA}}\right)$ were compared with both the aerosol column mass loading $\left(\mathrm{mg} \mathrm{m}^{-2}\right)$ and the $\tau_{\mathrm{CMAQ}}$ values calculated from the aerosol composition produced by the Models-3/CMAQ model. $\tau_{\mathrm{CMAQ}}$ was calculated based on the reconstructed extinction coefficient method (Sect. 3.3). In addition, $\tau_{\mathrm{CMAQ}}$ was averaged between 10:00 and 13:00 local sun time (LST), because the NASA Terra/MODIS measurements were taken approximately at 10:30 LST, passing over the East Asian domain for approximately $3-4 \mathrm{~h}$. In addition, the $\tau_{\mathrm{CMAQ}}$ values in the pixels where the $\tau_{\text {MODIS }}$ values were cloudfiltered were excluded. In Fig. 4, the spatial distributions of the averaged $\tau_{\mathrm{M}-\mathrm{BAER}}, \tau_{\mathrm{NASA}}, \tau_{\mathrm{CMAQ}}$, and aerosol column mass loading are shown for the four seasonal episodes. The high $\tau_{\mathrm{M} \text {-BAER }}$ and $\tau_{\text {NASA }}$ values appeared over four highly polluted areas: (i) Bohai Bay, (ii) Sichuan Basin, (iii) lower course of the Yangtze river (also called "Yangtze River Delta"), and (iv) high $\mathrm{NH}_{3}$ emission area (refer to Fig. 1). During the spring episode, a large dust storm broke out, and was transported over long distances through Manchuria and the Korean peninsula. Therefore, Fig. 4 shows a high aerosol mass loading over these areas during this episode (note that the scale of the column aerosol mass loading in spring was changed to better present the dust plume in Fig. 4). However, we observed high $\tau_{\text {MODIS }}$ over the Yellow Sea and the East Sea (also known as the Sea of Japan, refer to Fig. 1), but low $\tau_{\text {MODIS }}$ over Manchuria and the Korean peninsula. This may be related to the cloud pixel screening procedure in the AOD retrieval algorithms. Dust plumes are typically transported behind or below the cold frontal clouds in East Asia (e.g. Liu et al., 2002; Iino et al., 2004). During the spring episode, a dust storm erupted over the eastern parts of Inner Mongolia on 7 April 2002, and was transported out over Sakhalin and Hokkai Islands, passing through Manchuria and the Korean 

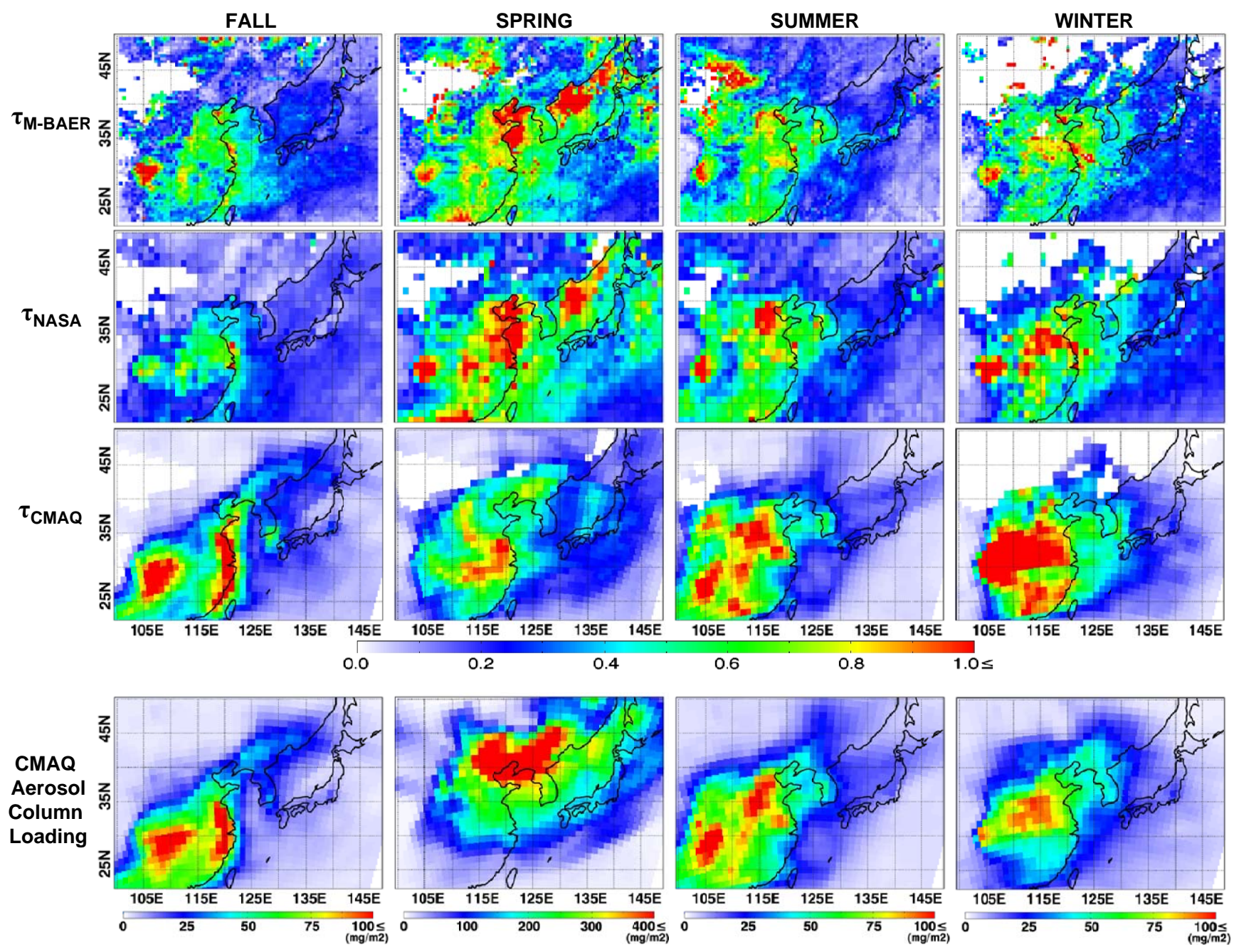

Fig. 4. Spatial distributions of averaged $\tau_{\mathrm{M}-\mathrm{BAER}}$ (top panels), $\tau_{\mathrm{NASA}}$ (panels in the second row), $\tau_{\mathrm{CMAQ}}$ (panels in the third row), and CMAQ-derived, aerosol column loading (panels in the fourth row) for the four seasons.

peninsula on 8 and 9 April 2002. Figure 5 shows snapshots of the infrared difference dust index (IDDI) with clouds from the NOAA satellite on 7 April to 9 April 2002. As shown in Fig. 5, the dust plumes were accompanied by clouds. Therefore, the many pixel values reflecting high dust concentrations were screened out. These procedures resulted in low average $\tau_{\mathrm{M}-\mathrm{BAER}}$ and $\tau_{\mathrm{NASA}}$ over Manchuria, as shown in Fig. 4. Further analysis of the dust plumes with TOMS AI is discussed in Sect. 4.1.2. Figure 4 also shows that $\tau_{\text {M-BAER }}$ and $\tau_{\text {NASA }}$ are higher than $\tau_{\text {CMAQ }}$ over the Yellow Sea and East Sea. This can be explained by three factors. First, the accurate quantities of mineral dust generated during the dust episode could not be estimated in this study. It should be noted that the amounts of mineral dust estimated by Eq. (1) may be lower than the actual level, which can in turn lead to small $\sigma_{\text {ext }}$ in Eq. (7), and thus a smaller $\tau_{\mathrm{CMAQ}}$ than $\tau_{\mathrm{MODIS}}$. On the other hand, as mentioned in Sect. 3.3, the amounts of $\alpha-\mathrm{Fe}_{2} \mathrm{O}_{3}$ in East Asian dust particles can be larger than those in the USA, which can affect the dry mass extinction efficiencies for fine- and coarse-mode dust particles in Eq. (7). Thirdly, the edge parts of the frontal clouds often cannot be filtered out using aerosol retrieval algorithms (e.g. Al-Saadi et al., 2005). Cloud droplets in the edges of the frontal clouds are highly reflective and are often misinterpreted as strong aerosol signals. The edges of the frontal clouds passed through the Yellow Sea and East Sea during the spring episode (this is partly shown in Fig. 5). The high $\tau_{\mathrm{M}-\mathrm{BAER}}$ and $\tau_{\mathrm{NASA}}$ over the Yellow Sea and East Sea might be influenced by the existence of the edge parts of frontal clouds. Overall, it is difficult to correctly retrieve or estimate the AOD values during dust storms in East Asia due to the uncertainty in predicting the amounts of mineral dust generated and/or the possible cloud effects accompanied by dust plumes. In addition, there was a clear discontinuity in

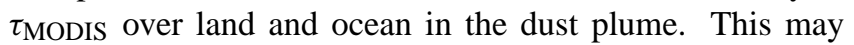
be caused by the different aerosol retrieval methods of the 

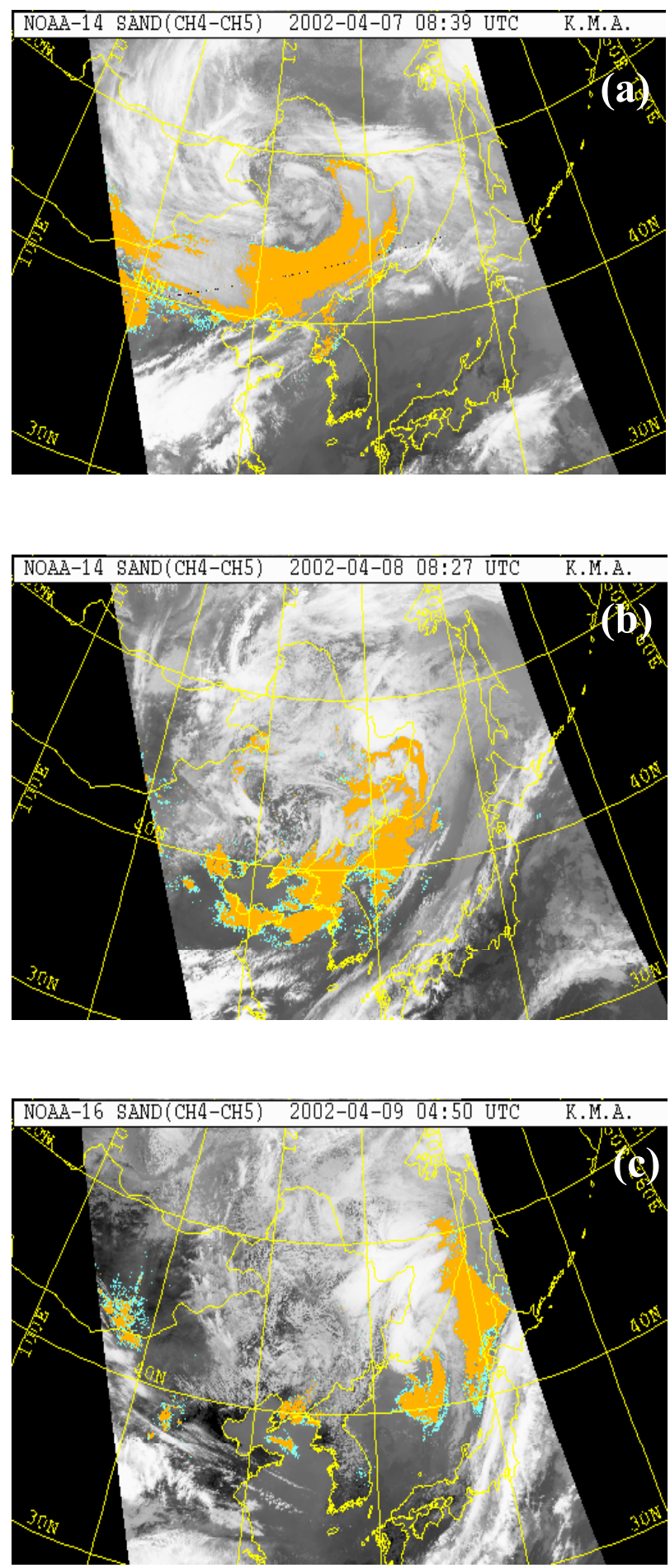

Fig. 5. Snapshots of the infrared difference dust index (IDDI) with clouds from the NOAA satellite: (a) 7 April, (b) 8 April, and (c) 9 April 2002. The yellow and white colors represent dust plumes and clouds, respectively.
M-BAER and NASA algorithms over the "land" and "ocean" (refer to Sect. 3.2).

In addition, no $\tau_{\text {MODIS }}$ values were reported over the desert and loess areas due to surface glint effects (cf. Fig. 1). The surface glint areas (white-colored areas in Fig. 4) were the largest in winter and many parts of the desert and loess areas were also covered by snow and ice during the winter season. In contrast, the grass-covered areas were the largest in summer, and thus the surface glint areas were shrunken during the summer episode. High $\tau_{\mathrm{M}-\mathrm{BAER}}$ values $\left(\tau_{\mathrm{M}-\mathrm{BAER}}>1.0\right)$ were also obtained, particularly around the desert areas. In contrast, the AOD values in $\tau_{\mathrm{NASA}}$ around the desert areas were reasonably low. As shown earlier, since the M-BAER algorithm deals with the surface reflectance with a combination of vegetation and soil, the strong reflectance over the bright pixels, such as the desert regions and urban and coastal areas, tend to produce strong aerosol signals (i.e. high biases), as shown in Fig. 4. In the NASA C005 algorithm, the values are considered missing values if the AOD values are $>3$ over and around the bright areas and are screened out.

Although the integrated satellite-CMAQ model analysis has many merits, further "chemical" analysis are still useful. $\tau_{\text {MODIS }}$ can provide the 2-D domain-wide, spatial distributions of columnar aerosol optical properties, but not the species-wise, spatially-resolved, aerosol chemical composition distributions. Therefore, the different aerosol formation characteristics in different regions and different seasons in East Asia could not be described or identified by $\tau_{\text {MODIS }}$ itself, and the analysis requires comprehensive CTM such as US EPA Models-3/CMAQ modeling in conjunction with the satellite-derived, aerosol optical properties. This is discussed in Sect. 4.1.3.

\subsubsection{Dust event and TOMS AI}

As discussed in Sect. 3.1, AI is a good optical indicator for absorbing aerosols (such as dust and BC), especially when they are transported through the "free" troposphere. Based on this, many scientists have investigated the ability of remotely sensed, high AI plumes concurrently occurring over the same regions to represent dust plumes transported over long-distances across the oceans and continents (Phadnis and Carmichael, 2000; Israelevich et al., 2002; Ginoux et al., 2001, 2004; Ginoux and Torres, 2003).

Snapshots for the spatial and temporal AI distributions during the dust period (7 to 9 April 2002) over East Asia are shown in the top three panels in Fig. 6. The transport of model-predicted, high column mass loading (mostly composed of dust particles) through Manchuria and the Korean peninsula are also presented in the bottom three panels in Fig. 6. Figure 6 illustrates the good agreements in the spatial and temporal distributions of both the high AI plumes and the high column mass loading (although both quantities are not directly compared to each other). 

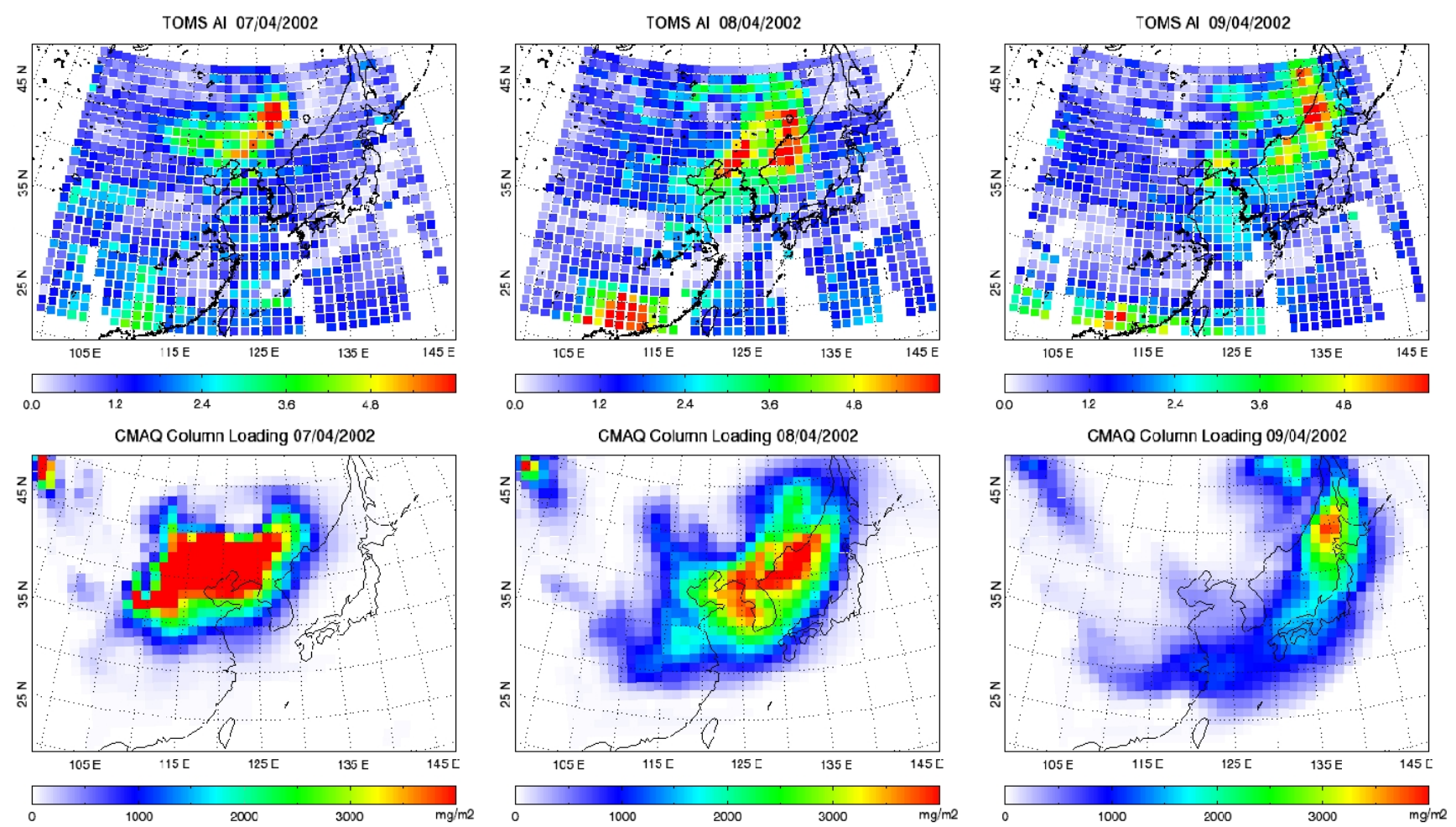

Fig. 6. Spatial and temporal distributions of TOMS AI (top panels) and model-predicted, column mass loading (bottom panels) during a dust storm period (from 7 to 9 April 2002) in East Asia.

In the top panels in Fig. 6, another high AI plume can be found over the Guangxi and Guangdong provinces (near Hong Kong). The high AI plume may have been caused by the BC plume emitted from biomass burning events. Spring is not only the typical dust season, but also the typical biomass burning season in East Asia (Ma et al., 2003; Song et al., 2005b, more references therein). The former usually influences the northeast Asian atmosphere, whereas the latter affects southeast Asian atmosphere, and frequently occurs in the southwestern edges of China, Thailand, Myanmar, and northern Vietnam. Since the biomass burning events took place outside the modeling domain, and as the CMAQ modeling does/can not consider the biomass burning event in the boundary conditions, the BC plumes over the Guangxi and Guangdong provinces were not captured in the results of the CMAQ modeling (regarding this point, refer to the bottom panels in Fig. 6, and also check the $\tau_{\text {MODIS values over the }}$ Guangxi and Guangdong provinces in the spring panels of Fig. 4).

\subsubsection{Seasonal and regional formation characteristics of particulate pollutants}

Figure 7 presents the spatial distributions of the column concentrations of five major particulate constituents of PM2.5: (i) nitrate $\left(\mathrm{NO}_{3}^{-}\right)$, (ii) sulfate $\left(\mathrm{SO}_{4}^{2-}\right)$, (iii) dust, (iv) $\mathrm{BC}$, and (v) SOAs. Although the spatial distribution of ammonium $\left(\mathrm{NH}_{4}^{+}\right)$is not shown in Fig. 7, it can be estimated from the column concentrations of nitrate and sulfate, because ammonium is present in fine-mode particles as forms of crystallized salt like $\mathrm{NH}_{4} \mathrm{NO}_{3}$ and $\left(\mathrm{NH}_{4}\right)_{2} \mathrm{SO}_{4}$, and/or is neutralized by nitrate and sulfate ions in the particulate water. The $\mathrm{NH}_{4} \mathrm{NO}_{3}$ salt formation or $\mathrm{NH}_{4}^{+}-\mathrm{NO}_{3}^{-}$ion association takes place by the following equilibrium reaction (Seinfeld and Pandis, 1998; Jacobson, 1999):

$$
\begin{aligned}
& \mathrm{NH}_{3}(\mathrm{~g})+\mathrm{HNO}_{3}(\mathrm{~g}) \leftrightarrow \mathrm{NH}_{4} \mathrm{NO}_{3}(\mathrm{~s}) \quad \text { and/or } \\
& \mathrm{NH}_{4}^{+}(\mathrm{aq})+\mathrm{NO}_{3}^{-}(\mathrm{aq})
\end{aligned}
$$

The equilibrium reaction of Reaction (R1) is governed by thermodynamic relationships. If the product of partial pressures of gas-phase $\mathrm{NH}_{3}$ and $\mathrm{HNO}_{3}$ is larger than the equilibrium constant $\left(K_{e q}\right)$, the equilibrium reactions proceed in the forward direction (i.e., the formation or association of $\mathrm{NH}_{4} \mathrm{NO}_{3}$ and/or $\mathrm{NH}_{4}^{+}-\mathrm{NO}_{3}^{-}$ions). On the contrary, if the product is smaller than $K_{e q}$, the equilibrium is governed by the reverse reaction. The equilibrium is also controlled by temperature, since $K_{e q}$ is a function of temperature. When temperature is low, the equilibrium tends to shift toward the particulate $\mathrm{NH}_{4} \mathrm{NO}_{3}$ and/or $\mathrm{NH}_{4}^{+}-\mathrm{NO}_{3}^{-}$formation, whereas, if temperature is high, it proceeds in the reverse direction. This heterogeneous process is considered by the ISORROPIA module in the Models-3/CMAQ model 

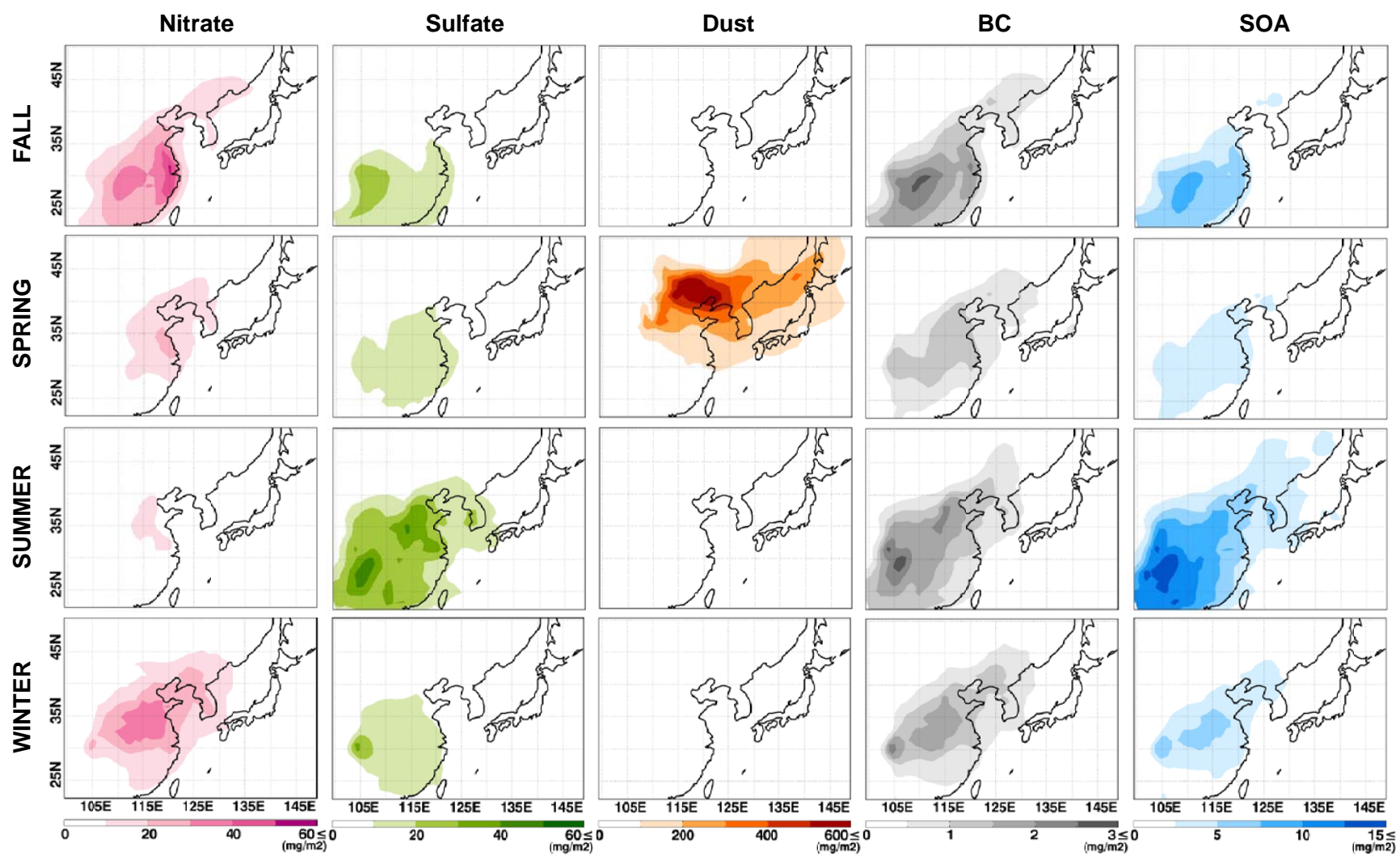

Fig. 7. Species-wise, spatial distributions of particulate components for the four seasons. Nitrate and sulfate concentrations in the first and second columns are associated with ammonium $\left(\mathrm{NH}_{4}^{+}\right)$in fine-mode particles. $\mathrm{BC}$ and SOAs denote black carbon and secondary organic aerosols, respectively.

(Nenes et al., 1998), and both forward and reverse reactions take place so rapidly that one can treat these processes in a thermodynamic manner, as described in Sect. 2.1 (Capaldo et al., 2000). In contrast, $\left(\mathrm{NH}_{4}\right)_{2} \mathrm{SO}_{4}$ formation and/or $\mathrm{NH}_{4}^{+}$$\mathrm{SO}_{4}^{2-}$ association take place in an "irreversible" way:

$$
\begin{array}{ll}
2 \mathrm{NH}_{3}(\mathrm{~g})+\mathrm{SO}_{4}^{2-}(\mathrm{aq})+2 \mathrm{H}^{+} \rightarrow\left(\mathrm{NH}_{4}\right)_{2} \mathrm{SO}_{4}(\mathrm{~s}) & \text { and } / \text { or } \\
2 \mathrm{NH}_{4}^{+}(\mathrm{aq})+\mathrm{SO}_{4}^{2-}(\mathrm{aq}) & (\mathrm{R} 2)
\end{array}
$$

Once sulfate is formed via $\mathrm{SO}_{2}+\mathrm{OH}$ reaction and subsequent gas-to-particle conversion, it is then neutralized by gas-phase $\mathrm{NH}_{3}$, following Reaction (R2).

Some amounts of nitrate and sulfate can also be formed in fine- and coarse-mode dust particles, in which nitrate and sulfate mainly exist as forms of $\mathrm{Ca}\left(\mathrm{NO}_{3}\right)_{2}$ and $\mathrm{CaSO}_{4}$. Song et al. (2005a, 2007), however, revealed that major parts ( $>95 \%$ on the mass basis) of $\mathrm{NH}_{4}^{+}-\mathrm{NO}_{3}^{-}-\mathrm{SO}_{4}^{2-}$ are mainly present in anthropogenic pollution particles and that they are almost externally mixed with chemically near-fresh dust particles in the East Asian atmosphere. Only small amounts of nitrate and sulfate can be formed in fine- and coarse-mode dust particles due to the small magnitudes of uptake coefficients of gas-phase sulfate and nitrate precursors (such as
$\mathrm{SO}_{2}, \mathrm{H}_{2} \mathrm{SO}_{4}, \mathrm{NO}_{3}, \mathrm{~N}_{2} \mathrm{O}_{5}$, and $\mathrm{HNO}_{3}$ ) onto East Asian mineral dust. Based on the conclusions of Song et al. (2005a, 2007), we neglect the nitrate and sulfate formation in/on dust particles in this study.

The first three columns in Fig. 7 present the spatial distributions of the nitrate, sulfate, and dust concentrations. As discussed previously, dust concentrations are large only in spring due to the dust storm. In Fig. 7, two facts are particularly noteworthy regarding the particulate $\mathrm{NH}_{4}^{+}-\mathrm{NO}_{3}^{-}-\mathrm{SO}_{4}^{2-}$ formation. First, the levels of nitrate (associated with ammonium) were almost comparable to those of sulfate (associated with ammonium). Thus, the $\mathrm{NH}_{4}^{+}-\mathrm{NO}_{3}^{-}$formation should not be neglected in the CTM studies, particularly over East Asia. Second, the $\mathrm{NH}_{4}^{+}-\mathrm{NO}_{3}^{-}$formation characteristics differed greatly from the $\mathrm{NH}_{4}^{+}-\mathrm{SO}_{4}^{2-}$ formation characteristics throughout the four seasons. Regarding the sulfate formation, the $\mathrm{SO}_{2}$ into sulfate conversion rate peaked in summer, because of the high temperature and high levels of hydroxyl radicals $(\mathrm{OH})$ due to the intense solar radiation and high levels of $\mathrm{H}_{2} \mathrm{O}$. Therefore, sulfate concentrations were the largest in summer and the smallest in winter. On the contrary, the fine-mode nitrate formation was active at low temperature. Thus, the levels of nitrate were the highest in winter and the 

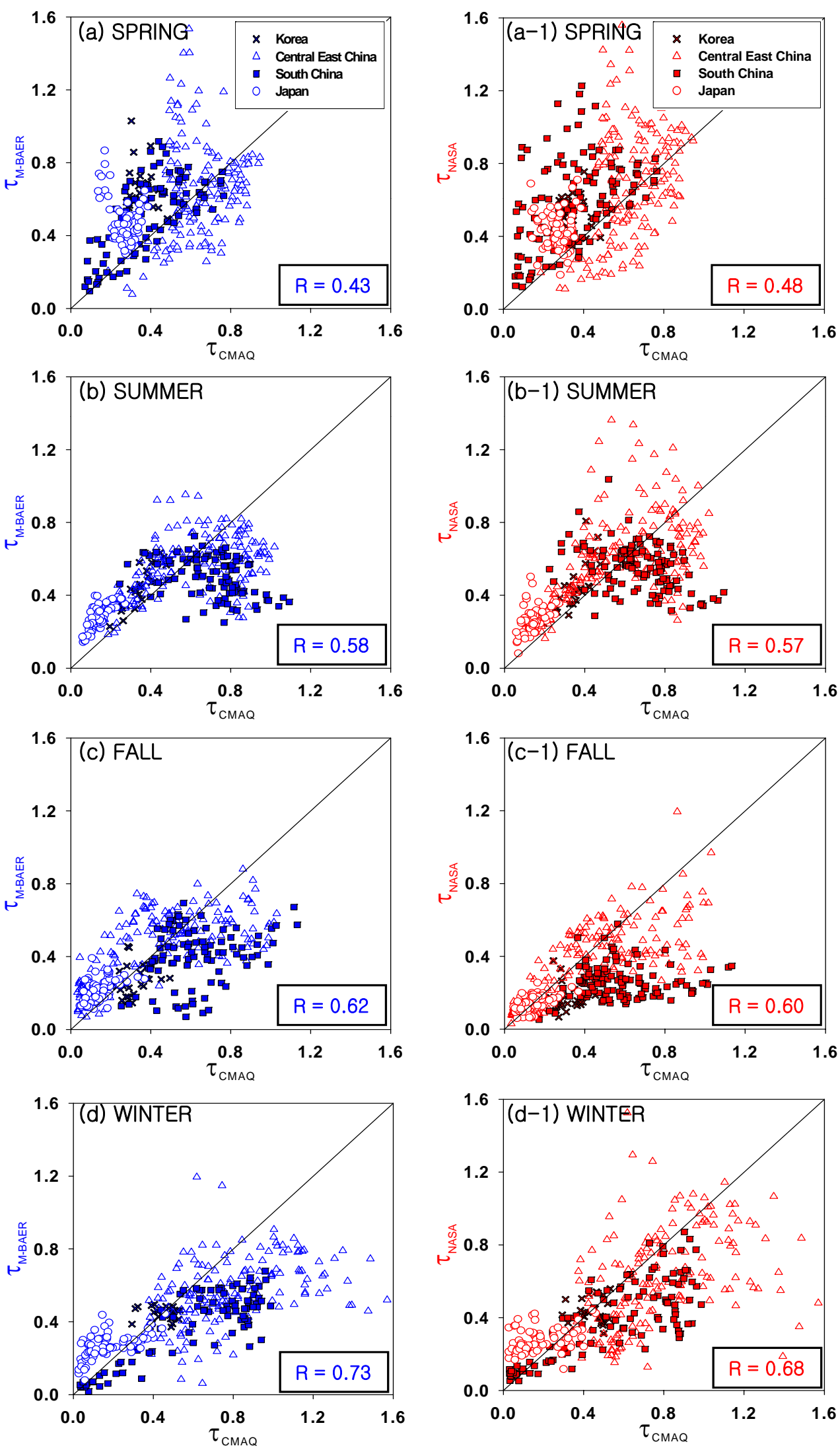

Fig. 8. Correlations between $\tau_{\mathrm{MODIS}}\left(\tau_{\mathrm{M}-\mathrm{BAER}}\right.$ and $\left.\tau_{\mathrm{NASA}}\right)$ and $\tau_{\mathrm{CMAQ}}$ for the four seasons: (a) Spring, (b) Summer, (c) Fall, and (d) Winter. 
lowest in summer. Both fine-mode sulfate and nitrate are the key particulate species that actually affect AOD $\left(\tau_{\text {MODIS }}\right.$ and $\left.\tau_{\mathrm{CMAQ}}\right)$ and therefore climate forcing by aerosols in East Asia. The contributions of both species to $\tau_{\text {MODIS }}$ and $\tau_{\mathrm{CMAQ}}$ increased with increasing RH, because both species are "hygroscopic", as described in Eq. (7). In addition, as mentioned above, the contributions of both species to $\tau_{\text {MODIS }}$ and $\tau_{\mathrm{CMAQ}}$ exhibited seasonal variations. In East Asia, $\left(\mathrm{NH}_{4}\right)_{2} \mathrm{SO}_{4}$ was the main contributor to large $\tau_{\mathrm{MODIS}}$ and $\tau_{\mathrm{CMAQ}}$ in summer, whereas $\mathrm{NH}_{4} \mathrm{NO}_{3}$ was in winter. Meanwhile, the extent of the contributions of both species also exhibited regional variations. $\mathrm{NH}_{4} \mathrm{NO}_{3}$ was usually formed over high $\mathrm{NH}_{3}$ emission areas (refer to Fig. 1), whereas $\left(\mathrm{NH}_{4}\right)_{2} \mathrm{SO}_{4}$ was formed mainly over the urban-polluted regions (regions $\mathrm{A}, \mathrm{B}$, and $\mathrm{C}$ in Fig. 1), since $\mathrm{SO}_{2}$ was mainly emitted from such areas. If the particulate species distributions in Fig. 7 are compared closely with the distributions of $\tau_{\mathrm{CMAQ}}$ in Fig. 4 for the four episodes, it can be seen that the distributions of $\tau_{\mathrm{CMAQ}}$ in East Asia are governed mainly by the formation of $\mathrm{NH}_{4}^{+}$$\mathrm{NO}_{3-}^{-}-\mathrm{SO}_{4}^{2-}$ (i.e., high $\tau_{\mathrm{CMAQ}}$ peaks occur with $\mathrm{NO}_{3}^{-}$and $\mathrm{SO}_{4}^{2-}$ peaks in Figs. 4 and 7).

$\mathrm{BC}$ is a light-absorbing particle. With the same mass concentration, its contribution to $\sigma_{\mathrm{ext}}$ and $\tau$ is large. Generally, the absolute $\mathrm{BC}$ levels are usually lower in East Asia than those of nitrate and sulfate. Since BC has similar emission sources to $\mathrm{SO}_{2}$, its spatial distributions are more similar to those of sulfate than those of nitrate.

The contributions of SOAs to $\sigma_{\mathrm{ext}}$ and $\tau$ were also considered to be large, as shown in Eq. (7). The absolute levels of SOAs in East Asia were approximately 0.25-0.33 times lower than those of sulfate and nitrate. The SOA formation is mainly governed by three factors: (i) temperature, (ii) the intensity of solar radiation, and (iii) the levels of precursors (i.e., NMVOCs). The SOA precursors react with $\mathrm{OH}$ radicals. The levels of $\mathrm{OH}$ radicals are primarily controlled by the intensity of solar radiation (Reaction R3), and are also limited by the levels of $\mathrm{H}_{2} \mathrm{O}$ (Reaction R4):

$\mathrm{O}_{3}+h v \rightarrow \mathrm{O}^{1 \mathrm{D}}+\mathrm{O}_{2}$

$\mathrm{O}^{1 \mathrm{D}}+\mathrm{H}_{2} \mathrm{O} \rightarrow 2 \mathrm{OH}$

NMVOCs $+\mathrm{OH}\left(\mathrm{O}_{3}\right.$ and $\left.\mathrm{NO}_{3}\right) \rightarrow$ SOAs (multi-steps)

The subsequent reaction of Reaction (R4) proceeds very fast, producing $\mathrm{OH}$ radicals in the atmosphere. The reaction rate of Reaction (R5) is controlled by the levels of $\mathrm{OH}$ radicals and increases with increasing temperature. Therefore, in general SOAs were actively produced in summer. There are other important routes for SOA production. NMVOCs react with other oxidants in the atmosphere, such as $\mathrm{O}_{3}$ and $\mathrm{NO}_{3}$. The concentrations of these two species are highest in summer and lowest in winter. In addition to the high levels of $\mathrm{OH}, \mathrm{O}_{3}$ and $\mathrm{NO}_{3}$, biogenic $\mathrm{NMVOC}$ emissions were also very active in summer. As mentioned in Sect. 2.3, we used the monthly biogenic isoprene and mono-terpene emissions from the GEIA inventory in the US EPA Models-3/CMAQ modeling study. The biogenic emissions were highly active in the southern parts of the Yangtze river. Thus, high levels of SOAs were found in the southern areas of the Yangtze river, and were the key particulate component that actually affected $\sigma_{\text {ext }}$, and thus $\tau_{\text {MODIS }}$ and $\tau_{\mathrm{CMAQ}}$, over such regions in summer (refer to the last column in Fig. 7).

\subsubsection{Statistical analysis}

This section presents an investigation into the correlation between $\tau_{\text {MODIS }}$ and $\tau_{\text {CMAQ }}$ over a pollution-affected window in the domain $\left(100^{\circ} \mathrm{E}-130^{\circ} \mathrm{E} ; 20^{\circ} \mathrm{N}-42^{\circ} \mathrm{N}\right)$. Remote ocean and continental areas were excluded from the analysis because we were primarily interested in the pollution-affected areas and did not consider the generation of sea-salt over the ocean.

Figure 8 shows scatter plots of $\tau_{\mathrm{CMAQ}}, \tau_{\mathrm{M}-\mathrm{BAER}}$, and $\tau_{\text {NASA. }}$. The three $\tau$ values were compared over four areas (Central East China, South China, Korea, and Japan). The Central East China (CEC) approximately includes high $\mathrm{NH}_{3}$ emission areas and Regions $\mathrm{A}$ and $\mathrm{C}$ in Fig. 1, and South China (SC) represents the areas located in the southern parts of the Yangtze river (Guangxi, Guangdong, Fujian, Hunan, Jiangxi provinces). As shown in Fig. 8, the scattered plots show seasonally and regionally different characteristics. In spring, many $\tau_{\mathrm{M}-\mathrm{BAER}}$, and $\tau_{\mathrm{NASA}}$ values were biased high compared with the $\tau_{\mathrm{CMAQ}}$ over CEC and SC (i.e., $\left.\tau_{\text {MODIS }}>\tau_{\text {CMAQ }}\right)$. This can be attributed to the influences of (i) dust storms over CEC and (ii) burning biomass plumes over SC during the spring episode. For example, biomass burning emissions occurred outside the domain was not considered in the CMAQ modeling but the biomass burning actually has an impact on the SC air quality, as shown in Figs. 4 and 6 , which enhance the levels of $\tau_{\mathrm{M}-\mathrm{BAER}}$, and $\tau_{\mathrm{NASA}}$. In addition, as discussed in Sect. 4.1.1, the uncertainty in predicting the ambient amounts of mineral dust and possible cloud effects may lead to the under-prediction of $\tau_{\text {MODIS }}$ over the Yellow sea. Both effects may result in high biases over CEC and SC in Fig. 8a and a-1. In contrast, low biases (i.e., $\tau_{\mathrm{CMAQ}}>\tau_{\mathrm{MODIS}}$ ) over $\mathrm{CEC}$ and $\mathrm{SC}$ were observed during fall and winter (cold seasons). A close examination of Figs. 4 and 7, suggests that the low biases are caused mainly by the excessive formation of $\mathrm{NH}_{4} \mathrm{NO}_{3}$. As mentioned in Sect. 2.3, the use of the official ACE-ASIA $\mathrm{NH}_{3}$ emission inventory tended to result in over-predictions of the particulate $\mathrm{NH}_{4} \mathrm{NO}_{3}$ concentrations (Kim et al., 2006). Such over-predictions can cause low biases over CEC and $\mathrm{SC}$ during the fall and winter episodes. Low biases were also observed over CEC and SC in summer. However, in the summer case, $\left(\mathrm{NH}_{4}\right)_{2} \mathrm{SO}_{4}$ formation appears to be responsible for the low biases (see Figs. 4 and 7). Since the ACE-ASIA $\mathrm{SO}_{2}$ emissions are believed to be relatively accurate (uncertainty of $\pm 16 \%$ was reported by Streets et al., 
Table 3. Statistical values among $\tau_{\mathrm{CMAQ}}, \tau_{\mathrm{M}-\mathrm{BAER}}$, and $\tau_{\mathrm{NASA}}$ over East Asia.

\begin{tabular}{|c|c|c|c|c|c|c|c|c|c|}
\hline & \multirow[b]{2}{*}{$\tau_{\text {CMAQ }}$ vs. } & \multicolumn{2}{|c|}{ RMSE } & \multicolumn{2}{|c|}{ MNGE } & \multicolumn{2}{|c|}{ MB } & \multicolumn{2}{|c|}{ MNB } \\
\hline & & $\tau_{\mathrm{M}-\mathrm{BAER}}$ & $\tau_{\mathrm{NASA}}$ & $\tau_{\mathrm{M}-\mathrm{BAER}}$ & $\tau_{\mathrm{NASA}}$ & $\tau_{\mathrm{M}-\mathrm{BAER}}$ & $\tau_{\mathrm{NASA}}$ & $\tau_{\mathrm{M}-\mathrm{BAER}}$ & $\tau_{\mathrm{NASA}}$ \\
\hline \multirow[t]{4}{*}{ Central East China ${ }^{\mathrm{a}}$} & Spring & 0.27 & 0.30 & 35.18 & 39.82 & -0.01 & -0.06 & 13.47 & 11.46 \\
\hline & Summer & 0.22 & 0.24 & 33.88 & 30.92 & 0.04 & -0.03 & 11.15 & 1.05 \\
\hline & Fall & 0.21 & 0.20 & 40.61 & 42.38 & -0.01 & 0.07 & -6.58 & 17.99 \\
\hline & Winter & 0.34 & 0.34 & 60.47 & 59.28 & 0.22 & 0.17 & 54.74 & 49.06 \\
\hline \multirow[t]{4}{*}{ South China ${ }^{b}$} & Spring & 0.20 & 0.33 & 27.78 & 38.73 & -0.12 & -0.23 & -20.62 & -36.04 \\
\hline & Summer & 0.31 & 0.28 & 60.67 & 45.92 & 0.21 & 0.12 & 52.64 & 31.65 \\
\hline & Fall & 0.31 & 0.39 & 99.50 & 151.85 & 0.23 & 0.33 & 96.07 & 151.31 \\
\hline & Winter & 0.27 & 0.24 & 65.75 & 55.47 & 0.21 & 0.14 & 63.40 & 34.72 \\
\hline \multirow[t]{4}{*}{ Korea $^{c}$} & Spring & 0.34 & 0.23 & 45.32 & 36.01 & -0.31 & -0.20 & -45.32 & -33.55 \\
\hline & Summer & 0.11 & 0.13 & 20.55 & 19.27 & -0.10 & -0.09 & -20.47 & -18.46 \\
\hline & Fall & 0.11 & 0.18 & 39.96 & 117.56 & 0.05 & 0.15 & 30.13 & 113.36 \\
\hline & Winter & 0.08 & 0.10 & 14.39 & 19.68 & 0.00 & 0.01 & 1.66 & 5.47 \\
\hline \multirow[t]{4}{*}{ Japan $^{\mathrm{d}}$} & Spring & 0.25 & 0.19 & 38.16 & 35.34 & -0.20 & -0.16 & -38.16 & -32.90 \\
\hline & Summer & 0.15 & 0.14 & 50.06 & 45.27 & -0.14 & -0.12 & -50.06 & -45.28 \\
\hline & Fall & 0.10 & 0.06 & 36.19 & 33.44 & -0.07 & -0.01 & -32.91 & -1.22 \\
\hline & Winter & 0.13 & 0.15 & 44.26 & 48.33 & -0.09 & -0.10 & -38.85 & -35.73 \\
\hline
\end{tabular}

a $28-42^{\circ} \mathrm{N}, 110-122^{\circ} \mathrm{E} ;{ }^{\mathrm{b}} 22-28^{\circ} \mathrm{N}, 100-119^{\circ} \mathrm{E} ;{ }^{\mathrm{c}} 35-40^{\circ} \mathrm{N}, 126-130^{\circ} \mathrm{E} ;{ }^{\mathrm{d}} 31-35^{\circ} \mathrm{N}, 130-135^{\circ} \mathrm{E} ; 34-38^{\circ} \mathrm{N}, 135-140^{\circ} \mathrm{E} ; 37-45^{\circ} \mathrm{N}$, $140-144^{\circ} \mathrm{E}$

2003), the over-predictions may not be due to $\mathrm{SO}_{2}$ emissions. Rather, the over-prediction may be related to overestimated values for $\mathrm{NH}_{3}$ emissions. In the CMAQ model, not only were overestimated $\mathrm{NH}_{3}$ emission fluxes over East Asia possibly used but constant $\mathrm{NH}_{3}$ fluxes were also assumed without considering the seasonal variations. On the other hand, summer is not a typical fertilizer application season in East Asia. Therefore, the virtual $\mathrm{NH}_{3}$ levels in the atmosphere during summer can be much higher than the real $\mathrm{NH}_{3}$ levels. Such high levels of $\mathrm{NH}_{3}$ lead to $\left(\mathrm{NH}_{4}\right)_{2} \mathrm{SO}_{4}$ formation in the CMAQ modeling with sufficient alkalinity in the atmosphere. However, if the virtual levels of $\mathrm{NH}_{3}$ are insufficient, highly active $\mathrm{SO}_{4}^{2-}$ production in summer would lead to the formation of acidic $\mathrm{NH}_{4} \mathrm{HSO}_{4}$ in East Asia, not $\left(\mathrm{NH}_{4}\right)_{2} \mathrm{SO}_{4}$ (e.g., Song and Carmichael, 1999). If this is the case, then $\tau_{\mathrm{CMAQ}}$ can be much lower during summer. However, this argument is a possibility, and further study on this issue is necessary.

Figure 8 also shows correlations between $\tau_{\text {MODIS }}$ and $\tau_{\mathrm{CMAQ}}$, with correlation coefficients $(R)$ ranging from 0.43 to 0.73. As shown in Fig. 8, the correlations between $\tau_{\mathrm{M}-\mathrm{BAER}}$ and $\tau_{\text {CMAQ }}$ are slightly better than those between $\tau_{\text {NASA }}$ and $\tau_{\mathrm{CMAQ}}$.

For further statistical investigations (error and bias analyses), four statistical parameters were introduced: (i) Root Mean Square Error (RMSE), (ii) Mean Normalized Gross Error (MNGE), (iii) Mean Bias (MB), and (iv) Mean Normalized Bias (MNB).

$$
\begin{aligned}
& \mathrm{RMSE}=\sqrt{\frac{1}{N} \sum_{1}^{N}\left(\tau_{\mathrm{CMAQ}}-\tau_{\mathrm{MODIS}}\right)^{2}} \\
& \mathrm{MNGE}=\frac{1}{N} \sum_{1}^{N}\left(\frac{\left|\tau_{\mathrm{CMAQ}}-\tau_{\mathrm{MODIS}}\right|}{\tau_{\mathrm{MODIS}}}\right) \times 100 \\
& \mathrm{MB}=\frac{1}{N} \sum_{1}^{N}\left(\tau_{\mathrm{CMAQ}}-\tau_{\mathrm{MODIS}}\right) \\
& \mathrm{MNB}=\frac{1}{N} \sum_{1}^{N}\left(\frac{\tau_{\mathrm{CMAQ}}-\tau_{\mathrm{MODIS}}}{\tau_{\mathrm{MODIS}}}\right) \times 100
\end{aligned}
$$

The results from the statistical analyses are presented in Table 3 for the four seasons over the four regions. In error analysis, the RMSEs (absolute errors) ranged from 0.06 (fall, over Japan) and 0.39 (fall, over SC), and the MNGEs (relative errors) between $14.39 \%$ (winter, over Japan) and $151.85 \%$ (fall, over SC). In bias analysis, the MBs (absolute biases) ranged from -0.31 (spring, over Korea) to 0.33 (fall, over SC), and the MNBs (relative biases) ranged from $-50.06 \%$ (summer, over Japan) to $151.31 \%$ (fall over SC). The statistical values shown in Table 3 are in general agreement with what has been discussed in this study. Therefore, several specific points will be discussed. Again, during spring, the biases (MBs and MNBs) are highly negative, reflecting the influences of dust and biomass burning events, as discussed above. Over Korea and Japan, these biases are also negative during summer. Indeed, two typhoons ("Sinlaku" and "Lusa") impacted the regions during summer (Kim 

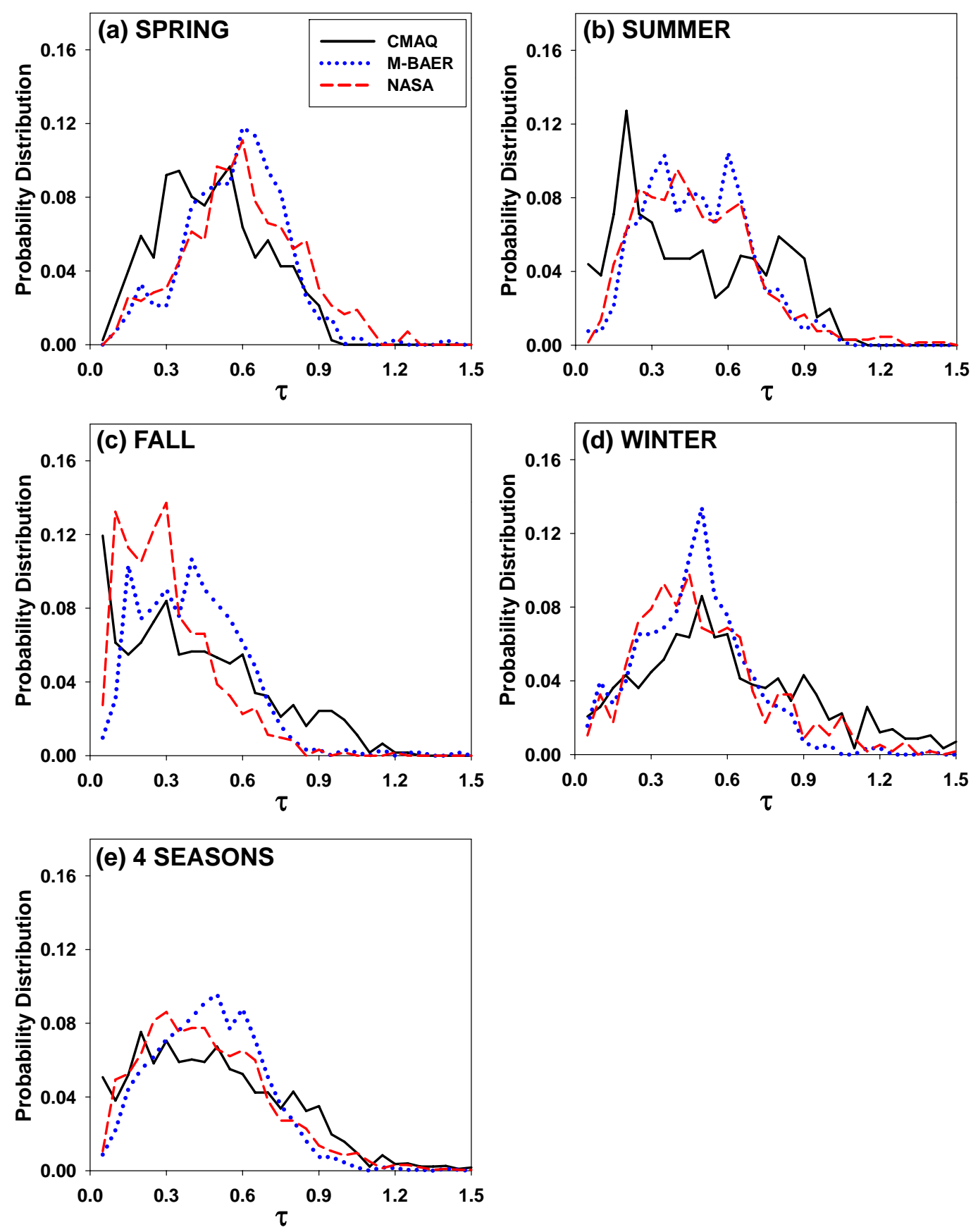

Fig. 9. Probability distribution function (PDF) of $\tau_{\text {MODIS }}\left(\tau_{\mathrm{M}}-\mathrm{BAER}\right.$ and $\left.\tau_{\mathrm{NASA}}\right)$ and $\tau_{\mathrm{CMAQ}}$ in the modeling domain for the four seasons: (a) Spring, (b) Summer, (c) Fall, (d) Winter, and (e) all seasons.

et al., 2007), and it is believed that the typhoon-induced high wind speeds generated large amounts of sea-salt that was not considered in the CMAQ modeling. This contributed to the negative biases in Table 3 over both regions. In addition, the biases were negative around all seasons in Japan. The AOD values are small over Japan ( $\tau<0.4$, except for spring). Hence, it was not noticed. However, these trends are also shown in Fig. 8. It is possible that the current ACE-ASIA emission inventory underestimated the anthropogenic emissions from Japan (cf. Uno et al., 2007). Again, as shown in Table 3, the magnitudes of the four statistical values between $\tau_{\mathrm{M}-\mathrm{BAER}}$ and $\tau_{\mathrm{CMAQ}}$ and between $\tau_{\mathrm{NASA}}$ and $\tau_{\mathrm{CMAQ}}$ are similar (except for the fall episode over SC and Korea), indicating that the M-BAER and NASA C005 algorithms have similar capability in producing $\tau$. 

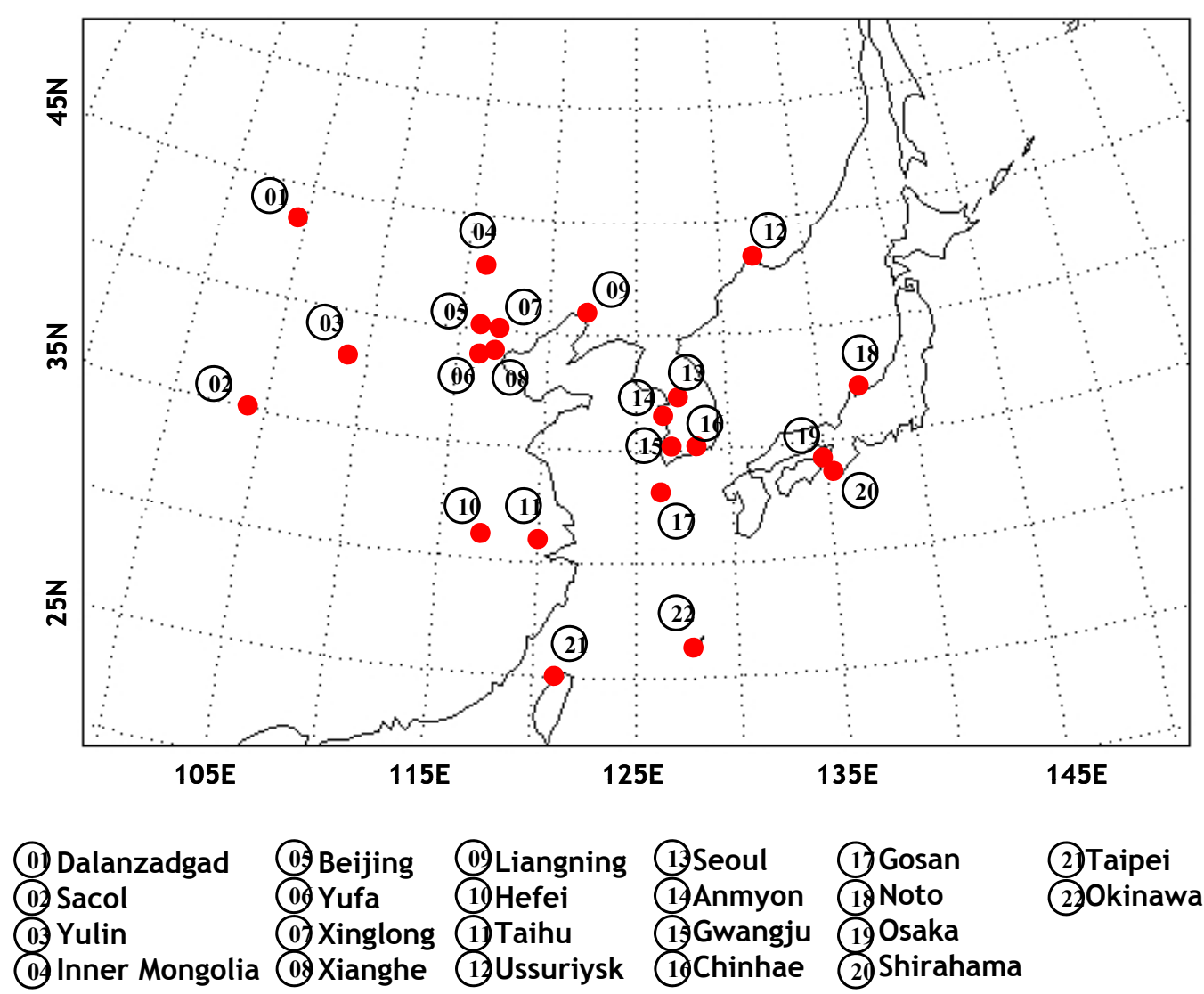

Fig. 10. AERONET sites in East Asia.

As discussed previously, except for the spring episode, the values of MBs and MNBs were positive over China, indicat-

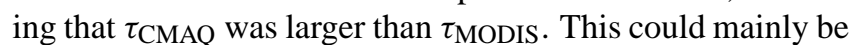
due to the overestimated $\mathrm{NH}_{3}$ emissions used in the CMAQ modeling. This may also have been partly attributed to the fact that the reconstructed extinction coefficient-based method reacts sensitively to $\mathrm{RH}$, particularly at $\mathrm{RH}>80 \%$. In addition, there are, of course, uncertainties in the M-BAER and NASA algorithms. Such results are contradictory to those reported by Chin et al. (2004) over East Asia during the ACE-Asia campaign period. Although they used different methods from those in this study, i.e., (i) $\tau_{\mathrm{NASA}} \mathrm{ob}-$ tained from the NASA Level-2 C004 products and (ii) Mietheory-based $\sigma_{\text {ext }}$ calculations, $\tau_{\text {NASA }}$ tended to be larger than $\tau_{\mathrm{GOCART}}$ (i.e., $\mathrm{MB}$ and MNB would be negative, if Eqs. (12) and (13) were employed in their study; here, GOCART is the name of the 3-D global CTM used by Chin et al., 2004). They interpreted these results by an explanation that $\tau_{\text {NASA }}$ from the NASA Level-2 C004 products tends to overestimate AOD, mainly due to the possible underestimation of the influences of the surface reflectance (Remer et al., 2005). Based on this, NASA released NASA Level-2 C005 products processed with an improved surface reflectance consid- eration (Levy et al., 2007). In addition, Chin et al.' work (2004) did not consider the particulate $\mathrm{NH}_{4} \mathrm{NO}_{3}$ formation in their global modeling, and thereby they also omitted the contribution of particulate $\mathrm{NH}_{4} \mathrm{NO}_{3}$ to $\sigma_{\text {ext }}$ and $\tau$. Although $\mathrm{NH}_{4} \mathrm{NO}_{3}$ formation in East Asia could be overestimated, as discussed in this section, the contribution of fine-mode $\mathrm{NH}_{4} \mathrm{NO}_{3}$ to $\sigma_{\text {ext }}$ and $\tau$ cannot be neglected in East Asia, and it should be taken into account in the 3-D CTM study over East Asia. Such omission of the $\mathrm{NH}_{4} \mathrm{NO}_{3}$ formation would lead to the under-predictions of $\tau_{\mathrm{GOCART}}$.

The distribution of $\tau_{\text {MODIS }}$ and $\tau_{\mathrm{CMAQ}}$ can also be compared by probability distribution function (PDF). The PDFs of $\tau_{\text {MODIS }}$ and $\tau_{\mathrm{CMAQ}}$ over the pollution-affected area, presented in Fig. 9, display highly similar shapes for the four seasons.

\subsection{CMAQ-, MODIS-derived AOD vs. AERONET AOD}

This section compares four different kinds of AOD ( $\tau_{\mathrm{CMAQ}}$, $\tau_{\mathrm{M}-\mathrm{BAER}}, \tau_{\mathrm{NASA}}$, and $\left.\tau_{\mathrm{AERONET}}\right)$ at several AERONET sites in East Asia. Particularly, $\tau_{\text {AERONET }}$ has been regarded as the "ground true value", since it is not interfered by surface reflectance (the largest uncertainty source in the retrieval of satellite-derived $\tau$ ). Therefore, the comparison studies 

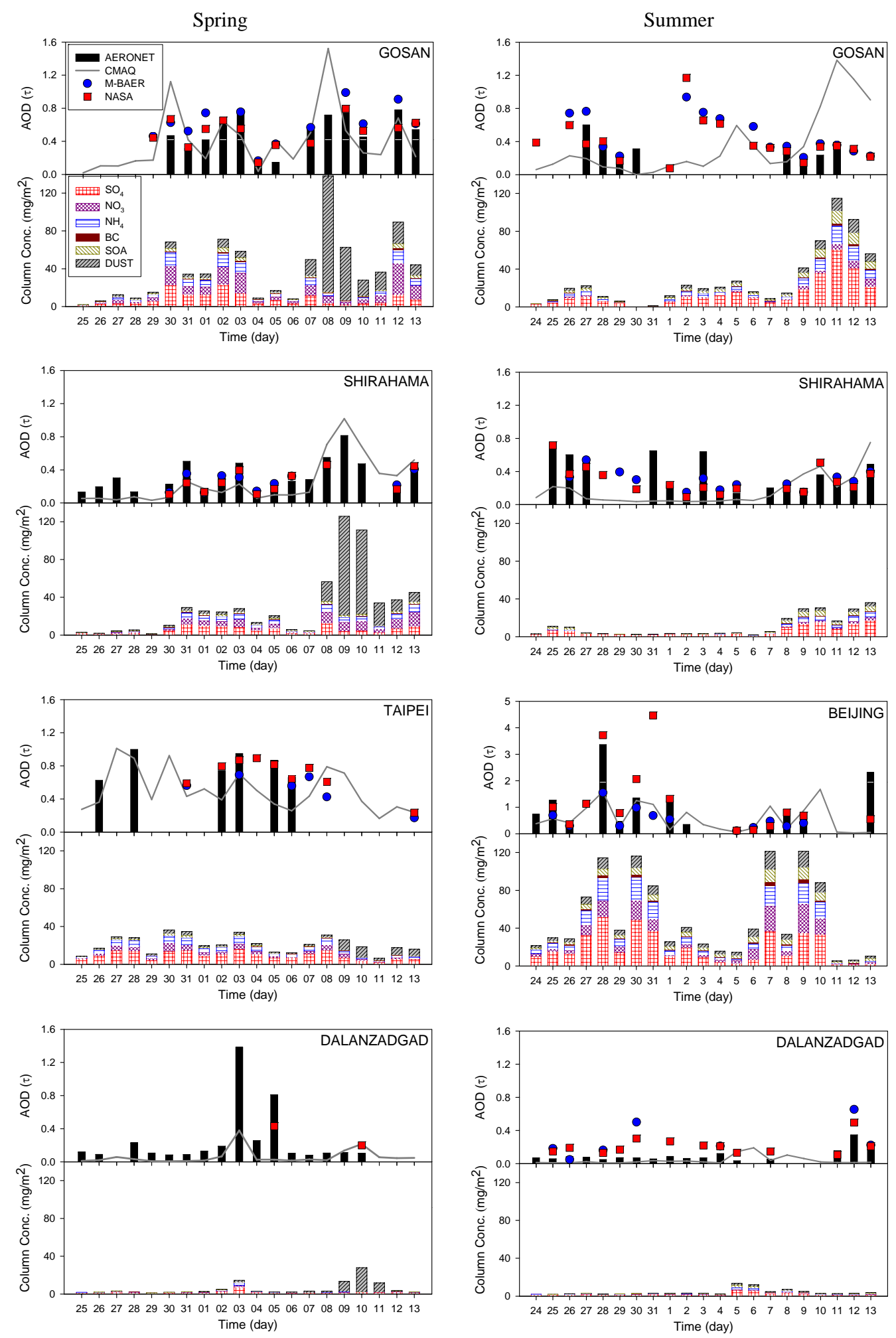

Fig. 11. Daily variations of $\tau_{\mathrm{AERONET}}, \tau_{\mathrm{CMAQ}}, \tau_{\mathrm{M}-\mathrm{BAER}}$, and $\tau_{\mathrm{NASA}}$ (upper panels) and daily variations of CMAQ-derived particulate composition (bottom panels) in several AERONET sites in East Asia for the four seasons. At the upper panel of each figure, the black bars, solid lines, red circles, and blue squares represent $\tau_{\mathrm{AERONET}}, \tau_{\mathrm{CMAQ}}, \tau_{\mathrm{M}-\mathrm{BAER}}$, and $\tau_{\mathrm{NASA}}$, respectively. In each season, the four sites with the largest number of $\tau_{\mathrm{AERONET}}$ were selected. 
Fall
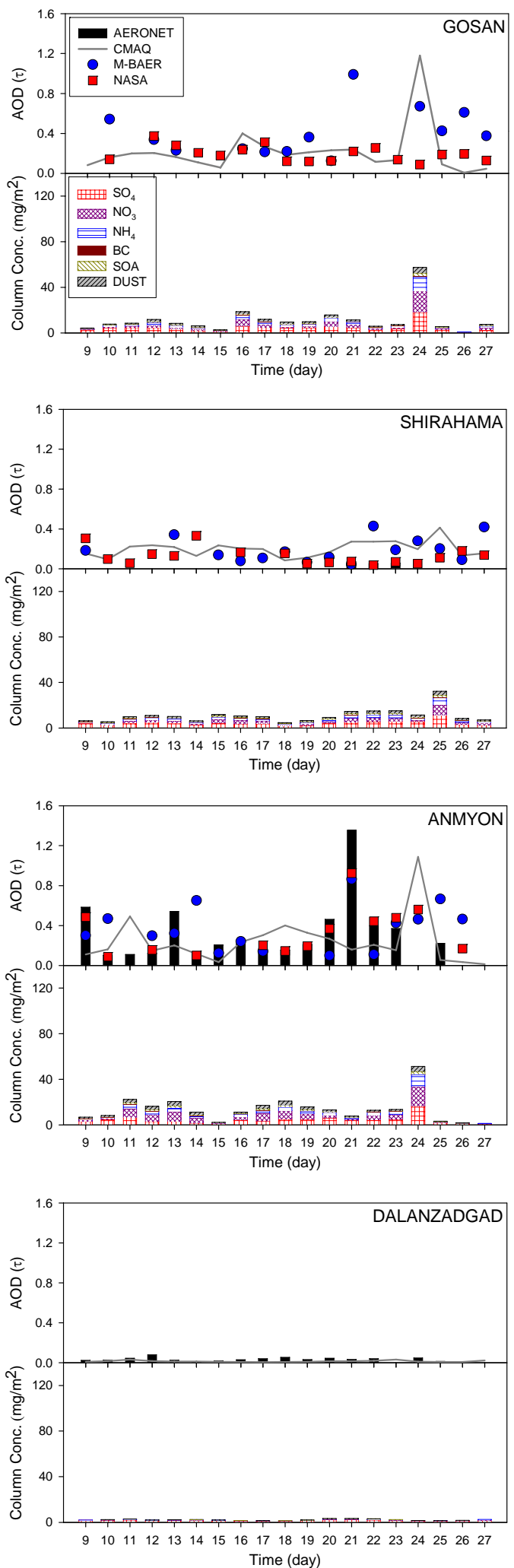

Winter
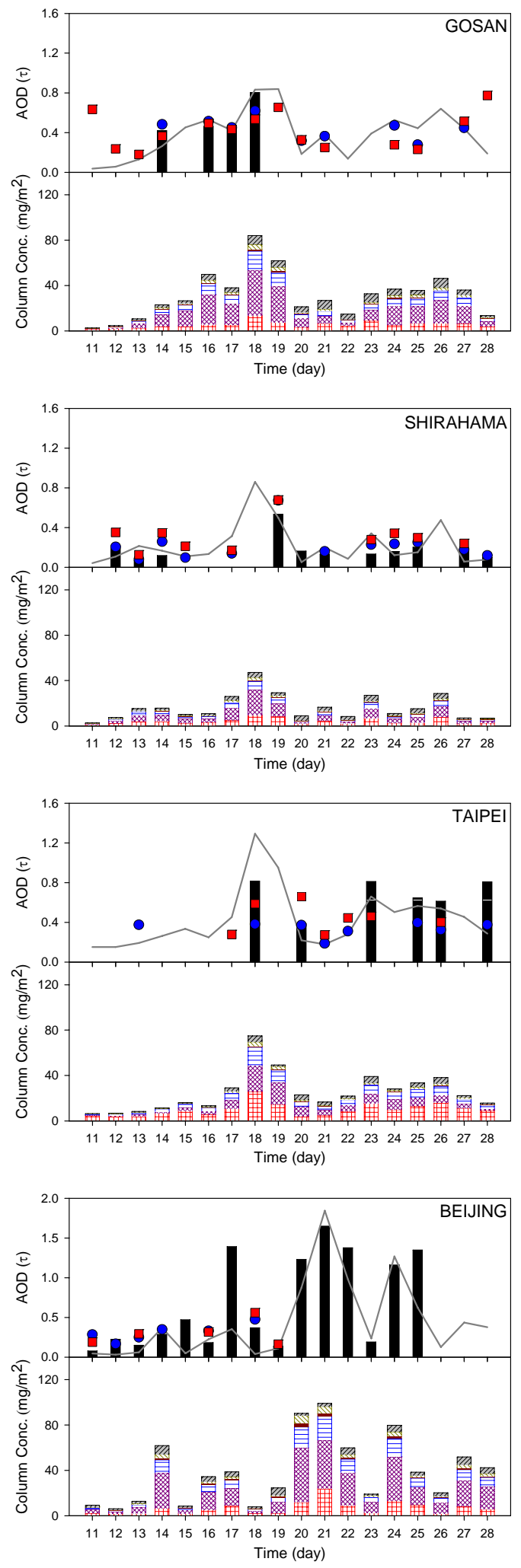

Fig. 11. Continued. 
(a) SPRING

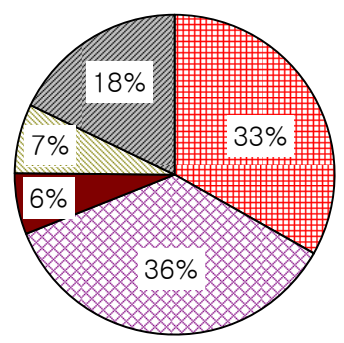

(c) FALL

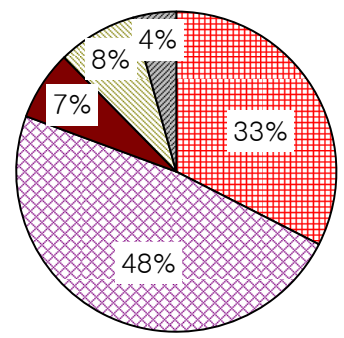

$\mathrm{SO}_{4}^{2-} \otimes \mathrm{NO}_{3}^{-} \square \mathrm{BC}$

Fig. 12. Contributions of particulate species to $\sigma_{\text {ext }}$ and $\tau_{\mathrm{CMAQ}}$ : (a) Spring, (b) Summer, (c) Fall, and (d) Winter. The contributions were calculated using Eq. (7) at the AERONET sites of the domain.

between $\tau_{\text {MODIS }}$ and $\tau_{\text {AERONET }}$ may be able to provide a good opportunity to evaluate the accuracy of the M-BAER and NASA algorithms and US EPA Models-3/CMAQ modeling over East Asia.

AERONET has 22 ground-based monitoring stations in East Asia (Fig. 10) which provide total column spectral $\tau$ at visible and NIR wavelengths. As discussed previously, we selected $\tau$ at $550 \mathrm{~nm}$ for these comparison studies. The comparisons among the four different types of $\tau$ are shown in Fig. 11 (upper panel of each figure). The selections of the AERONET sites were based on the AERONET data availability in each season (i.e., in each season, the four sites with the largest number of $\tau_{\text {AERONET }}$ were chosen). The particulate "chemical" composition generated from US EPA Models-3/CMAQ modeling is also plotted in Fig. 11 (bottom panel of each Figure), which exhibits the good agreement among $\tau_{\mathrm{CMAQ}}, \tau_{\mathrm{M}-\mathrm{BAER}}, \tau_{\mathrm{NASA}}$, and $\tau_{\mathrm{AERONET}}$. This issue will be further analyzed below.

During the spring episode, the peaks at the Gosan and Shirahama sites on 7 to 9 April 2002 were predominantly affected by the dust storm, and the influence lasted till 13 April 2002. During the non-dust period, however, $\tau_{\mathrm{CMAQ}}$, $\tau_{\mathrm{M}-\mathrm{BAER}}, \tau_{\mathrm{NASA}}$, and $\tau_{\mathrm{AERONET}}$ appeared to be mainly in- fluenced by secondary anthropogenic inorganic compounds such as ammonium, nitrate, and sulfate, as discussed in Sect. 4.1.3, whereas the contribution of SOAs was relatively small. Again, the contribution of sea-salt particles to $\tau$ may have been important, since the two sites were located in coastal areas. However, in US EPA Models-3/CMAQ modeling, the sea-salt emissions were not considered. Unlike the Gosan and Shirahama sites, the influence of dust particles is negligible in Taipei, and $\tau$ is largely impacted by secondary inorganic compounds. At the Dalanzadgad site, $\tau_{\text {MODIS }}$ was hardly observed, since Dalanzadgad is located inside the Gobi desert (i.e., due to the surface glint effects over the desert areas). $\tau_{\text {AERONET }}$ available at the Dalanzadgad site showed two salient peaks on 3 and 5 April 2002, but they were not predicted by the dust generation model (Eq. 1). In practice, predictions and forecasts of dust storms have been difficult and very challenging (Gillette and Passi, 1988; Gillette et al., 1992; Park and Lee, 2004; Uno et al., 2006). The dust generation model used in this study can predict large- or regional-scale dust storms like the one that erupted on 7 to 9 April 2002 over Manchuria, but not the local-scale dust events that take place inside the Gobi desert and loess plateau areas.

Unlike the spring season, several $\tau_{\text {MODIS }}$ were retrieved at the Dalanzadgad site in summer due to the spreading of grass-covered areas in this area (also refer to Fig. 4). Nevertheless, the magnitude of $\tau$ in Dalanzadgad was small, due to its location in a remote continental background area. In contrast, $\tau$ in Beijing was large and appeared to be primarily affected by $\left(\mathrm{NH}_{4}\right)_{2} \mathrm{SO}_{4}$ and secondarily by $\mathrm{NH}_{4} \mathrm{NO}_{3}$ in summer (note that in Fig. 11 (summer), the y-axis in Beijing has been re-scaled). Gosan was also greatly affected by $\left(\mathrm{NH}_{4}\right)_{2} \mathrm{SO}_{4}$ and $\mathrm{NH}_{4} \mathrm{NO}_{3}$ on 9 to 13 September 2002. In particular, the Gosan site was strongly influenced by typhoon "Sinlaku" from 2 to 8 September 2002 (Kim et al., 2007). Sea-salt generation due to the high wind speeds would be so

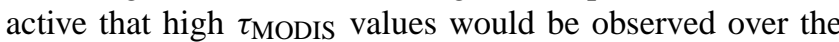
period. However, again the generation of sea-salt was not considered in the CMAQ modeling, which caused a discrepancy between $\tau_{\text {MODIS }}$ and $\tau_{\mathrm{CMAQ}}$ over the "Sinlaku" typhoon period in Fig. 11 (summer). The magnitude of $\tau$ in winter was also large, but the contributions of particulate chemical species were changed. As shown in Fig. 11 (winter), $\tau$ from Beijing to Shirahama was more affected by the formation of $\mathrm{NH}_{4} \mathrm{NO}_{3}$ than of $\left(\mathrm{NH}_{4}\right)_{2} \mathrm{SO}_{4}$. In fall, not many $\tau_{\mathrm{AERONET}}$ were available except at the Anmyon site, where both $\left(\mathrm{NH}_{4}\right)_{2} \mathrm{SO}_{4}$ and $\mathrm{NH}_{4} \mathrm{NO}_{3}$ almost equally contributed to $\tau$.

Although Fig. 11 shows the particulate column composition at a limited number of the AERONET sites, it did not show the contribution from each particulate species to $\sigma_{\text {ext }}$ and $\tau_{\mathrm{CMAQ}}$. Figure 12 shows the contribution of each particulate species to $\sigma_{\mathrm{ext}}$ and $\tau_{\mathrm{CMAQ}}$ (i.e., $\sigma_{\mathrm{ext}}$ and $\tau_{\mathrm{CMAQ}}$ budget) at the 22 AERONET sites shown in Fig. 10 (here, the contributions were estimated from the terms at the right-hand side 

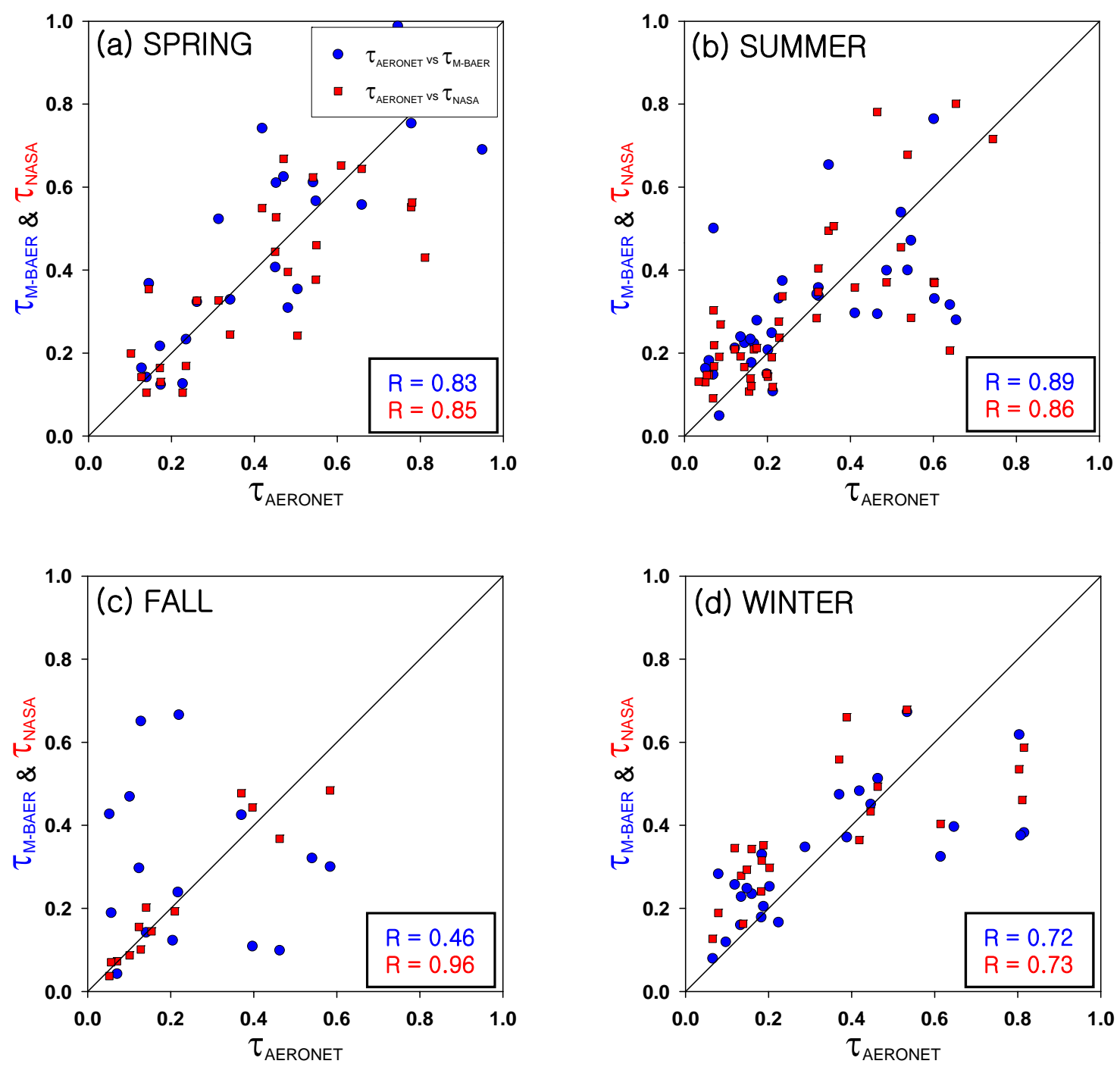

Fig. 13. Correlations between $\tau_{\text {AERONET }}$ and $\tau_{\text {MODIS }}$ in the four seasons: (a) Spring, (b) Summer, (c) Fall, and (d) Winter.

of Eq. (7), and were averaged in a mass-weighted manner). In summer $\left(\mathrm{NH}_{4}\right)_{2} \mathrm{SO}_{4}$ and SOAs made a $60 \%$ and $15 \%$ contribution to $\sigma_{\text {ext }}$ and $\tau_{\mathrm{CMAQ}}$, respectively, whereas in fall and winter (cold seasons), $\mathrm{NH}_{4} \mathrm{NO}_{3}$ was the main contributor (although it may have been overestimated in the CMAQ modeling). In spring, the contributions of $\left(\mathrm{NH}_{4}\right)_{2} \mathrm{SO}_{4}, \mathrm{NH}_{4} \mathrm{NO}_{3}$, and dust particles to $\tau_{\mathrm{CMAQ}}$ were similar. It should be emphasized that the "contribution of $\mathrm{NH}_{4} \mathrm{NO}_{3}$ " in the aerosol optical properties should not be neglected, particularly in East Asia, as shown in Fig. 12.

In addition, we compared $\tau_{\mathrm{M}-\mathrm{BAER}}$ and $\tau_{\mathrm{NASA}}$ with $\tau_{\text {AERONET }}$ at several AERONET sites in East Asia to evaluate the performance of the M-BAER and NASA algorithms in East Asia. First, the correlations between $\tau_{\text {MODIS }}$ and $\tau_{\text {AERONET }}$ were analyzed in Fig. 13 for the four seasons. The two quantities were highly correlated to each other around the 1:1 lines with correlation coefficients $(R)$ ranging from 0.72 to 0.96 (except for $R$ between $\tau_{\mathrm{M}-\mathrm{BAER}}$ and $\tau_{\mathrm{AERONET}}$ in the Fall). The reason for the low $R$ value (highly scattered $\tau_{\mathrm{M}-\mathrm{BAER}}$ with reference to $\tau_{\mathrm{AERONET}}$ ) in the fall is unclear but it may partly be due to the availability of $\tau_{\text {AERONET }}$. As shown in Fig. 11, there were only limited days during which $\tau_{\text {MODIS }}$ and $\tau_{\text {AERONET }}$ were available simultaneously. In particular, during the fall episode, $\tau_{\text {AERONET }}$ was available only at Anmyon station, and the quantity of data was also limited. This can affect the low $R$ in the fall, and should be investigated further.

As previously discussed, since 2006 NASA has released new satellite aerosol products, denoted as NASA Level$2 \mathrm{C} 005$, which are reported to have reduced the levels of $\tau_{\text {NASA }}$, compared with $\tau_{\text {NASA }}$ (NASA C004 product), and thus show better agreement with $\tau_{\text {AERONET }}$ (Dubovik et al., 
Table 4. Statistical values among $\tau_{\mathrm{CMAQ}}, \tau_{\mathrm{M}-\mathrm{BAER}}, \tau_{\mathrm{NASA}}$, and $\tau_{\mathrm{AERONET}}$ at the AERONET sites in East Asia.

\begin{tabular}{|c|c|c|c|c|c|c|c|c|c|c|c|c|}
\hline \multirow[b]{2}{*}{${ }^{\tau_{\text {CMAQ }}}$ vs. $^{\mathrm{a}}$} & \multicolumn{3}{|c|}{ RMSE } & \multicolumn{3}{|c|}{ MNGE } & \multicolumn{3}{|c|}{$\mathrm{MB}$} & \multicolumn{3}{|c|}{ MNB } \\
\hline & $\tau_{\mathrm{M}-\mathrm{BAER}}$ & $\tau_{\mathrm{NASA}}$ & $\tau_{\text {AERONET }}$ & $\tau_{\mathrm{M}-\mathrm{BAER}}$ & $\tau_{\mathrm{NASA}}$ & $\tau_{\text {AERONET }}$ & $\tau_{\mathrm{M}-\mathrm{BAER}}$ & $\tau_{\mathrm{NASA}}$ & $\tau_{\text {AERONET }}$ & $\tau_{\mathrm{M}-\mathrm{BAER}}$ & $\tau_{\mathrm{NASA}}$ & $\tau_{\text {AERONET }}$ \\
\hline Spring & 0.25 & 0.24 & 0.29 & 45.51 & 41.88 & 61.95 & -0.11 & -0.10 & -0.11 & -21.67 & -18.11 & -31.44 \\
\hline Summer & 0.39 & 0.65 & 0.52 & 82.23 & 83.57 & $78.85^{`}$ & -0.06 & -0.21 & -0.16 & -9.90 & -20.06 & -22.29 \\
\hline Fall & 0.30 & 0.26 & 0.26 & 78.63 & 119.04 & 96.55 & -0.10 & 0.02 & -0.05 & 10.10 & 73.68 & 11.73 \\
\hline Winter & 0.21 & 0.26 & 0.27 & 49.63 & 54.31 & 54.67 & -0.01 & -0.06 & -0.11 & -1.17 & -12.09 & -29.05 \\
\hline \multicolumn{13}{|c|}{ vs. $\tau_{\text {AERONET }}^{\mathrm{b}}$} \\
\hline Spring & 0.14 & 0.14 & - & 30.84 & 27.88 & - & 0.03 & -0.03 & - & 13.67 & 0.02 & - \\
\hline Summer & 0.38 & 0.32 & - & 65.75 & 62.77 & - & -0.09 & -0.00 & - & 33.99 & 39.71 & - \\
\hline Fall & 0.29 & 0.13 & - & 153.54 & 20.29 & - & 0.02 & -0.03 & - & 109.08 & -0.72 & - \\
\hline Winter & 0.17 & 0.17 & - & 43.69 & 62.50 & - & -0.01 & 0.04 & - & 23.96 & 47.79 & - \\
\hline
\end{tabular}

a indicates that $\tau_{\text {CMAQ }}$ was used as the test variable in Eqs. (10-13). ${ }^{\mathrm{b}}$ indicates that $\tau_{\mathrm{AERONET}}$ was used as the reference variable in Eqs. (10-13).

2002; Remer et al., 2005; Levy et al., 2007; Li et al., 2007). As shown in Fig. 13, with reference to $\tau_{\text {AERONET }}$ (ground true value), both $\tau_{\mathrm{M}-\mathrm{BAER}}$ and $\tau_{\mathrm{NASA}}$ (NASA C005 product) were highly correlated around the 1:1 lines during the four seasons. This suggests that: i) both M-BAER and NASA algorithms can produce a high quality $\tau_{\text {MODIS }}$ and ii) the accuracy of $\tau_{\mathrm{M}-\mathrm{BAER}}$ is almost equivalent to that of $\tau_{\mathrm{NASA}}$. This was further confirmed by statistical analysis.

RMSE, MNGE, MB, and MNB among $\tau_{\text {M-BAER }}$ and $\tau_{\text {NASA }} \tau_{\text {CMAQ }}$ and $\tau_{\text {AERONET }}$ were analyzed in Table 4 . Although the largest differences appeared in the fall episode, $\tau_{\mathrm{CMAQ}}, \tau_{\mathrm{M}-\mathrm{BAER}}$, and $\tau_{\mathrm{NASA}}$ and $\tau_{\mathrm{AERONET}}$ exhibited good agreements in the other three seasons. Again, the large differences in fall could be partly caused by the scarcity of $\tau_{\text {AERONET }}$ during the fall episode. Importantly, no significant positive biases $\left(\tau_{\text {MODIS }} \gg \tau_{\text {AERONET }}\right)$ were reported, which have been typical in the analyses of $\tau_{\text {MODIS }}$ vs. $\tau_{\text {AERONET }}$ (Chin et al., 2004; Remer et al., 2005; Levy et al., 2007). This may indicate that both $\tau_{\mathrm{M}-\mathrm{BAER}}$ and $\tau_{\mathrm{NASA}}(\mathrm{C} 005)$ can capture the spatial and seasonal aerosol characteristics in East Asia better than $\tau_{\mathrm{NASA}}(\mathrm{C} 004)$.

\section{Summary and conclusions}

The spatio-temporal and seasonal distributions of $\tau_{\text {MODIS }}$ $\left(\tau_{\text {M-BAER }}\right.$ and $\left.\tau_{\text {NASA }}\right)$ were compared with those of aerosol column mass loading $\left(M_{\text {column }}\right)$ and $\tau_{\mathrm{CMAQ}}$ for the four seasonal episodes in East Asia. Although $\tau_{\text {MODIS }}$ can provide information on spatial aerosol mass distributions, they can not provide aerosol chemical composition. Therefore, in order to estimate the aerosol chemical composition over East Asia, the US EPA Models-3/CMAQ v4.3 model was utilized, together with the PSU/NCAR MM5 meteorological model and the ACE-Asia/TRACE-P official emission inventory for East Asia. In this study, $\tau_{\mathrm{CMAQ}}$ was calculated using a reconstructed extinction coefficient-based method, whereas $\tau_{\text {MODIS }}$ was retrieved from MODIS Level-1B (L1B) radiance data using a modified Bremen Aerosol Retrieval Algorithm (M-BAER algorithm) and NASA Collection 5 (C005) algorithm. In addition, $\tau_{\text {AERONET }}$ from several AERONET sites in East Asia was obtained and used as the "ground true value" in this study.

Both $\tau_{\mathrm{MODIS}}$ and $\tau_{\mathrm{CMAQ}}$ showed high values around Chinese urban and industrial centers, such as Sichuan Basin, Bohai Bay and Yangtze Delta areas, as well as over active agriculture and livestock farming areas due to their high $\mathrm{NH}_{3}$ emissions. For the four season episodes selected in this study, the CMAQ model in general generated similar levels of $\tau_{\mathrm{CMAQ}}$ to those of $\tau_{\text {MODIS }}$ throughout the domain. However, during the spring episode, $\tau_{\mathrm{CMAQ}}$ was significantly under-predicted compared to $\tau_{\text {MODIS }}$, thereby showing negative biases, particularly over the areas where dust storm and burning biomass plumes had traveled. Unlike the spring episode, the levels of $\tau_{\mathrm{CMAQ}}$ were generally higher than those of $\tau_{\text {MODIS. Through US EPA Models-3/CMAQ }}$ modeling, this study investigated the contribution of each particulate chemical species to $\tau_{\text {MODIS }}$ and $\tau_{\text {CMAQ }}$. During the summer episode, the high levels of both $\tau_{\text {MODIS }}$ and $\tau_{\mathrm{CMAQ}}$ may have been caused mainly by the high concentrations of $\left(\mathrm{NH}_{4}\right)_{2} \mathrm{SO}_{4}$ produced over the Chinese urban and industrial centers. In contrast, the high $\tau_{\text {MODIS }}$ and $\tau_{\mathrm{CMAQ}}$ plumes during the late fall and winter episodes were related to $\mathrm{NH}_{4} \mathrm{NO}_{3}$ concentrations over the urban and industrial centers, as well as over Chinese agricultural and livestock farming areas. These results suggest that the formation of both $\left(\mathrm{NH}_{4}\right)_{2} \mathrm{SO}_{4}$ and $\mathrm{NH}_{4} \mathrm{NO}_{3}$ were over-predicted over China, possibly due to the overestimated values for $\mathrm{NH}_{3}$ emissions used in the CMAQ modeling. This might in turn cause strong biases $\left(\tau_{\mathrm{CMAQ}}>\tau_{\mathrm{MODIS}}\right)$. Finally, $\tau_{\mathrm{MODIS}}$ was greatly correlated with $\tau_{\mathrm{AERONET}}$, indicating the promising potential of the application of the M-BAER algorithm to East Asian air quality and satellite-based monitoring studies.

In future analysis, given the recent capability for aerosol optical products to be retrieved with fine resolutions, 3-D photochemistry-aerosol modeling should be conducted with 
matching fine resolutions, possibly by employing a nestedgrid technique (Byun and Ching, 1999). In addition, US EPA has released a "spin-off" version of the CMAQ model, called the CMAQ-MADRID (Model of Aerosol Dynamics, Reaction, Ionization, and Dissolution) model (Zhang et al., 2002, 2004; Pun et al., 2005). The CMAQ-MADRID model still uses the US EPA Models-3/CMAQ frame, but includes alternative aerosol dynamic, microphysical, and chemical processes. As the CMAQ-MADRID model has a more sophisticated SOA formation scheme than the CMAQ model (Zhang et al., 2004; Pun et al., 2002, 2005), the use of the former may produce a different particulate chemical composition and therefore different $\tau_{\mathrm{CMAQ}}$-MADRID.

In the remote sensing of aerosol optical properties, various types of aerosol optical properties (such as $\tau, \omega_{o}, \alpha$, FMF, and $r_{\text {eff }}$ ) are becoming available at higher qualities. For example, FMF was not considered in this study because it has not yet been included in the M-BAER algorithm. However, future studies should consider and attempt to identify the changes in the aerosol size-distribution by using satellitederived FMF, $\alpha$, and/or $r_{\text {eff }}$. Furthermore, although satellite remote sensing has a serious limitation in obtaining vertical aerosol extinction profiles, space-borne lidar systems such as CALIPSO have released vertically resolved, spectral aerosol extinction profiles since 2006. The availability of such data will provide further opportunities for atmospheric modelers and the monitoring community to investigate aerosol formation and transport characteristics on both regional and global scales.

Acknowledgements. This work was funded by the Korea Meteorological Administration Research and Development Program under Grant CATER 2006-3201 in Korea.

Edited by: K. Lehtinen

\section{References}

Ackerman, S. A., Strabla, K. I, Menzel, W. P., Frey, R. A., Moeller, C. C, and Gumley, L. E.: Discriminating clear sky from clouds with MODIS, J. Geophys. Res., 103(D24), 32 141-32 157, 1998.

Akimoto, H.: Global air quality and pollution, Science, 362(5651), 1716-1719, 2003.

Al-Saadi, J., Szykman, J., Pierce, R. B., Kittaka, C., Neil, D., Chu, D., Remer, L., Gumley, L., Prins, E., Weinstock, L., MacDonald, C., Wayland, R., Dimmick, F., and Fishman, J.: Improving national air quality forecasts with satellite aerosol observations, B. Am. Meteorol. Soc., 86, 1249-1261, 2005.

Binkowski, F. S.: Aerosols in Models-3/CMAQ, EPA/600/R99/030, 1999.

Binkowski, F. S. and Roselle, S. J.: Models-3 Community Multi-scale Air Quality (CMAQ) model aerosol components: 1. model description, J. Geophys. Res., 108(D6), 4183, doi:10.1029/2001JD001409, 2003.

Bucholtz, A.: Rayleigh-scattering calculations for the terrestrial atmosphere, Appl. Optics, 34, 2765-2773, 1995.
Byun, D. W. and Ching, J. K. S.: Science Algorithm of the EPA Models-3 Community Multi-scale Air Quality(CMAQ) Modeling System. EPA/600/R-99/030, USEPA, Research Triangle Park, USA, 1999.

Byun, D. W. and Schere, K. L.: Review of the governing equations, computational algorithm, and other components of the Models-3 Community Multi-scale Air Quality (CMAQ) Modeling system, Appl. Mecha. Rev., 59(2), 51-77, 2006.

Capaldo, K., Pilinis, C., and Pandis, S. N.: A computationally efficient hybrid approach for dynamic gas/aerosol transfer in air quality models, Atmos. Environ. 34, 3617-3627, 2000.

Charlson, R. J., Schwartz, S. E., Hales, J. M., Cess, R. D., Coakley Jr., J. A., Hansen, J. E., and Hoffmann, D. J.: Climate forcing by anthropogenic aerosols, Science, 255, 423-430, 1992.

Colarco, P. R., Toon, O. B., Torres, O., and Rasch, P. J.: Determining the UV imaginary index of refraction of Saharan dust particles from Total Ozone Mapping Spectrometer data using a three-dimensional model of dust transport, J. Geophys. Res., 107(D16), 4289, doi:10.1029/2001JD000903, 2002.

Conant, W. C., Seinfeld, J. H., Wang, J., et al.: A model for the radiative forcing during ACE-Asia derived from CIRPAS Twin Ottor and R/V Ronald H. Brown data and omposition with observations, J. Geophys. Res., 108(D23), 8661, doi:10.1029/2002JD003206, 2003.

Chin, M., Ginoux, P., Kinne, S., Torres, O., Holben, B. N., Duncan, B. N., Martin, R. V., Logan, J. A., Higurashi, A., and Nakajima, T.: Tropospheric aerosol optical thickness from the GOCART model and comparisons with satellite and sunphotometer measurements, J. Atmos. Sci., 59, 461-483, 2001.

Chin, M., Chu, A., Levy, R., Remer, L., Kaufman, Y., Holben, B., Eck, T., Ginoux, P., and Gao, Q.: Aerosol distribution in the Northern Hemisphere during ACE-Asia: Results from global model, satellite observations, and Sun photometer measurements, J. Geophys. Res., 109, D23S90, doi:10.1029/2004JD004829, 2004.

d'Almeida, G. A., Koepke, P., and Shettle, E. P.: Atmospheric Aerosols: Global climatology and Radiative Characteristics, A. Deepak Publishing, Hampton, Virginia, USA, p.100, 1991.

Dubovik, O., Holben, B. N., Eck, T. F., Smirnov, A., Kaufman, Y. J., King, M. D., Tanre, D., and Slutsker, I.: Variability of absorption and optical properties of key aerosol types observed in worldwide locations, J. Atmos. Sci. 59(3), 590-608, 2002.

Gillette, D. and Passi, R.: Modeling dust emission caused by wind erosion, J. Geophys. Res., 93, 14 233-14 242, 1988.

Gillette, D., Stensland, G., Williams, A., Barnard, W., Gatz, D., Sinclair, P., and Johnson, T.: Emissions of alkaline elements: calcium, magnesium, potassium, and sodium from open sources in the contiguous Unite States, Global Biogeochem. Cycles, 6, 437-457, 1992.

Ginoux, P., Chin, M., Tegen, I., Prospero, J., Holben, B., Dubovik, O., and Lin, S.-J.: Sources and distributions of dust aerosols simulated with the GOCART model, J. Geophys. Res., 106(20), 225-273, 2001.

Ginoux, P. and Torres, O.: Empirical TOMS index for dust aerosol: Application to model validation and source characterization, J. Geophys. Res., 108(D17), 4534, doi:10.1029/2003JD003470, 2003.

Ginoux, P., Prospero, J. M., Torres, O., and Chin, M.: Long-term simulation of global dust distribution with the GOCART model: 
Correlation with North Atlantic Oscillation, Environ. Modell. Softw., 19, 113-128, 2004.

Grell, G. A., Dudhia, J., and Stauffer, D. R.: A description of the fifth-generation Penn State/NCAR mesoscale model (MM5), NCAR Technical Note, NCAR/TN-398+ST, 1994.

Herman, J. R., Bhartia, P. K., Torres, O., Hsu, C., Seftor, C., and Celarier, E.: Global distribution of UV absorbing aerosols from Nimbus7/TOMS data. J. Geophys. Res., 102, 16911-16922, 1997.

Hess, M., Koepke, P., and Schult, I: Optical properties of aerosols and clouds: The software package OPAC, B. Am. Meteorol. Soc., 79, 831-844, 1998.

Holben, B. N., Eck, T. F., Sluster, I., et al.: AERONET: A federated instrument network and data archive for aerosol characterization, Rem. Sens. Environ., 66, 1-16, 1998.

Holben, B. N., Tanre, D., Smirnov, A., et al.: An emerging ground-based aerosol climatology: Aerosol optical depth from AERONET, J. Geophys. Res., 106, 12 067-12 097, 2001.

Hsu, N. C., Herman, J. R., and Tsay, S.: Radiative impacts from biomass burning in the presence of clouds during boreal spring in southeast Asia, Geophys. Res. Lett., 30(5), 1224, doi:10.1029/2002GL016485, 2003.

Husar, R. B., Tratt, D. M., Schichtel, B. A., et al.: Asian dust events of April 1998, J. Geophys. Res., 106(D16), 18 317-18 330, 2001.

Iino, N., Kinoshita, K., Tupper, A. C., and Yano, T.: Detection of Asian dust aerosols using meteorological satellite data and suspended particulate matter concentrations, Atmos. Environ., 38, 6999-7008, 2004.

Israelevich, P. L., Levin, Z., Joseph, J. H., and Ganor, E.: Desert aerosol transport in the Mediterranean region as inferred from the TOMS aerosol index, J. Geophys. Res., 107(D21), 4572, doi:10.1029/2001JD002011, 2002.

Jacobson, M. Z.: Fundamentals of atmospheric modeling, Cambridge University Press, New York, 478-480, 1999.

Karnieli, A., Kaufman, Y. J., Remer, L. A., and Ward, A.: AFRI Aerosol free vegetation index, Rem. Sens. Environ., 77, 10-21, 2001.

Kaufman, Y. J., Wald, A. E., Remer, L. A., Gao, B. C., Li, R. R., and Flynn, L.: The MODIS 2.1 channel - Correlation with visible reflectance for use in remote sensing of aerosol. IEEE Trans. Geosci. Remote Sens., 35, 1286-1298, 1997.

Kaufman, Y. J., Tanre, D., and Boucher, O.: A satellite view of aerosols in the climate system, Nature, 419, 215-223, 2002.

Kim, D., Sohn, B., Nakajima, T., Takamura, T., Takemura, T., Choi, B., and Yoon, S.: Aerosol optical properties over east Asia determined from ground-based sky radiation measurements, J. Geophys. Res., 109, D02209, doi:10.1029/2003JD003387, 2004.

Kim, J. Y., Song, C. H., Ghim, Y. S., Won, J. G., Yoon, S.-C., Carmichael, G. R., and Woo, J. H.: An investigation on $\mathrm{NH}_{3}$ emissions and particulate $\mathrm{NH}_{4}^{+}$and $\mathrm{NO}_{3}^{-}$formation in East Asia, Atmos. Environ., 40(12), 2139-2150, 2006.

Kim, J. Y., Ghim, Y. S., Song, C. H. ,Yoon, S.-C., and Han, J. S.: Seasonal characterization of air masses arriving at Gosan, Korea, using fine particle measurements between November 2001 and August 2003, J. Geophys. Res., 112, D07202, doi:10.1029JD006946, 2007.

King, M. D., Kaufman, Y. J., Tanre, D., and Nakajima, T.: Remote sensing of tropospheric aerosols from space: Past, present, and future, B. Am. Meteorol. Soc., 80, 2229-2259, 1999.
Kokhanovsky, A. A., von Hoyningen-Huene, W., and Burrow, J. P.: Atmospheric aerosol load from space, Atmos. Res., 81, 176-185, 2006.

Lee, K. H., Kim, J. E., Kim, Y. J., Kim, J., and von HoyningenHuene, W.: Impact of the smoke aerosol from Russian forest fires on the atmospheric environment over Korea during May 2003, Atmos. Environ., 39, 85-99, 2005.

Lee, K. H., Kim, Y. J., and Kim, J. M.: Characteristics of aerosol observed during two severe haze events over Korea in June and October 2004, Atmos. Environ, 40, 5146-5155, 2006 a.

Lee, K. H., Kim, Y. J., von Hoyningen-Huene, W., and Burrow, J. P.: Influence of land surface effects on MODIS aerosol retrieval using the BAER method over Korea, Int. J. Rem. Sens., 27(14), 2813-2830, 2006b.

Lee, K. H., Kim, Y. J., von Hoyningen-Huene, W., and Burrow, J. P.: Spatio-temporal variability of satellite-derived aerosol optical thickness over Northeast Asia in 2004, Atmos. Environ., 41, 3959-3973, 2007.

Levy, R. C., Remer, L. A., Mattoo, S., Vermote, E. F., and Kaufman, Y. J.: A second-generation operational algorithm: Retrieval of aerosol properties over land from inversion of MODIS reflectance, J. Geophys. Res., 112, D13211, doi:10.1029/2006JD007811, 2007.

Li, R. R., Remer, L., Kaufman Y. J., et al.: Snow and ice mask for the MODIS aerosol products, IEEE Geosci. Rem. Sens. Lett., 2(3), 306-310, 2005.

Li, Z, Niu, F., Lee, K. H., Xin, J., Hao, W., Nordgren, B., Wang, Y., Wang, P.: Validation and understanding of MODIS aerosol products using ground-based measurements from the handheld sunphotometer network in China, J. Geophys. Res., 112, D22S07, doi:10.1029/2007JD008479, 2007.

Liu, M., Westphal, D. L., Wang, S., Shimizu, A., Sugimoto, N., Zhou, J., and Chen, Y.: A high-resolution numerical study of the Asian dust storms of April 2001, J. Geophys. Res., 108(D23), 8653, doi:10.1029/2002JD003178, 2003.

Ma, J., Richiter, A., Burrow, J. P., Nüß, H., and van Aardenne, J. A.: Comparison of model-simulated tropospheric $\mathrm{NO}_{2}$ over China with GOME-satellite data, Atmos. Environ., 40, 593-604, 2006.

Ma, Y., Rodney, R. J., Lee, Y.-N., Thornton, D. C., Bandy, A. R., Clarke, A. D., Blake, D. R., Sachse, G. W., Fuelberg, H. E., Kiley, C. M., Woo, J.-H., Streets, D. G., Carmichael, G. R., and Eisele, F. L.: The characteristics and influence of biosmoke on fine particle ionic composition measured in Asian outflow during TRACE-P, J. Geophys. Res., 108, 8816, doi:10.1029/2002JD003128, 2003.

Malm, W. C., Sisler, J. F., Huffman, D., Eldred, R. A., and Cahill, T. A.: Spatial and seasonal trends in particle concentration and optical extinction in the United States, J. Geophys. Res., 99, 13471370, 1994.

Malm, W. C. and Kreidenweis, S. M.: The effects of models of aerosol hygroscopicity on the apportionment of extinction, Atmos. Environ., 31, 1965-1976, 1997.

Malm, W. C.: Spatial and seasonal patterns and temporal variability of haze and its constituents in the United States: Report III (Chapter 3), US EPA, 1-38, 2000.

Mattis, I., Ansmann, A., Althausen, D., Jaenisch, V., Wandinger, U., Muller, D., Arshinov, Y. F., Bobrovnikov, S. M., and Serikov, I.: Relative humidity profiling in the troposphere with a Raman lidar, Appl. Optics, 41(30), 6451-6462, 2002. 
Martins, J. V., Tanré, D., Remer, L., Kaufman, Y., Mattoo, S., and Levy, R.: MODIS cloud screening for remote sensing of aerosols over oceans using spatial variability. Geophys. Res. Lett., 29(12), 8009, doi:10.1029/2001GL013252, 2002.

McPeters, R. D., Bhartia, P. K., Krueger, A. J., et al.: Nimbus7 Total Ozone Mapping Spectrometer (TOMS) data products user's guide, NASA Ref. Publ., 1384, 1996.

Nenes, A., Pandis, S. N., and Pilinis, C.: ISORROPIA: a new thermodynamic equilibrium model for multiphase multicomponent inorganic aerosols, Aquatic Geochemistry, 4, 123-152, 1998.

Park, S.-U. and Lee, E. J.: Parameterization of Asian dust (Hwangsa) particle-size distributions for use in dust emission models, Atmos. Environ., 38, 2155-2162, 2004.

Phadnis, M. J. and Carmichael, G. R.: Numerical investigation of the influence of mineral dust on the tropospheric chemistry of East Asia, J. Atmos. Chem., 36, 285-323, 2000.

Pun, B. K., Griffin, R. J., Seigneur, C., and Seinfeld, J. H.: Secondary organic aerosol: 2. Thermodynamic model for gas/particle partitioning of molecular constituents. J. Geophys. Res., 107(D17), 4333, doi:10.1029/2001JD000542, 2002.

Pun, B., Karamchandani, P., Vijayaraghavan, K., Chen, S.-Y., and Seigneur, C.: Models-3/Community Multiscale Air Quality Model (CMAQ) User's Guide to Alternative Modules: Model of Aerosol Dynamics, Reaction, Ionization, and Dissolution (MADRID), Mercury (Hg), and Advanced Plume Treatment (APT), Document Number CP194-05-1, EPRI, Palo Alto, CA, 2005.

Ramanathan, V. and Crutzen, P. J.: New Directions: Atmospheric Brown Clouds, Atmos. Environ., 37, 4033-4035, 2003.

Ramanathan, V., Ramanathan, M. V., Roberts, G., Kim, D., Corrigan, C., Chung, C., and Winker, D.: Warming trend in Asia amplified by brown cloud solar absorption, Nature, 448, 575-579, doi:10.1038/nature06019, 2007.

Reisner, J., Rasmussen, R. J., and Bruintjes, R. T.: Explicit forecasting of subcooled liquid water in winter storms using the MM5 mesoscale model, Q. J. Roy. Meteorol. Soc., 124B, 1071-2554, 1998.

Remer, L. A., Kaufman, Y. J., Tanre, D., Mattoo, S., Chu, D. A., Martins, J. V., Li, R-R., Ichoku, C., Levy, R. C., Kleidman, R. G., Eck, T. F., Vermote, E., and Holben, B. N.: The MODIS Aerosol Algorithm, Products and Validation, J. Atmos. Sci., 62, 947-973, 2005.

Seinfeld, J. H. and Pandis, S. N.: Atmospheric chemistry and physics, A Wiley-Interscience Publication, New York, USA, 1998.

Seinfeld, J. H., Carmichael, G. R., Arimoto, R., et al.: ACE-ASIA: Regional climate and atmospheric chemical effects of Asian dust and pollution, B. Am. Meteorol. Soc., 85, 367-380, 2004.

Singh, H. B. and Jacob, D. J.: Future Directions: Satellite observations of tropospheric chemistry, Atmos. Environ., 34, 43994401, 2000.

Song, C. H. and Carmichael, G. R.: The aging processes of naturally-emitted aerosol (sea-salt and marine aerosol) during long range transport, Atmos. Environ., 33, 2203-2218, 1999.

Song, C. H. and Carmichael, G. R.: A three-dimensional modeling investigation of the evolution processes of dust and sea-salt particles in East Asia, J. Geophys. Res., 106, 18 131-18 154, 2001a.

Song, C. H. and Carmichael, G. R.: Gas-particle partitioning of nitric acid modulated by alkaline aerosol, J. Atmos. Chem., 40,
1-22, 2001b.

Song, C. H., Maxell-Meier, K., Rodney, R. J., Kapustin, V., and Clarke, A.: Dust composition and mixing state inferred from airborne composition measurements from ACE-Asia C130 Flight\#6, Atmos. Environ., 39, 359-369, 2005a.

Song, C. H., Ma, Y., Orsini, D., Kim, Y. P., and Weber, R. J.: An investigation into the ionic chemical composition and mixing state of biomass burning particles recorded during TRACE-P P3B Flight \#10, J. Atmos. Chem., 51, 43-64, 2005 b.

Song, C. H., Kim, C. M., Lee, Y. J., Carmichael, G. R., Lee, B. K., and Lee, D. S.: An evaluation of reaction probabilities of sulfate and nitrate precursors onto East Asian dust particles, J. Geophys. Res., 112, D18206, doi:10.1029/2006JD008092, 2007.

Stauffer, D. R. and Seaman, N. L.: Use of four-dimensional data assimilation in a limited-area mesoscale model. Part I: experiments with synoptic-scale data, Mon. Weather Rev., 118(6), 1250-1277, 1990.

Stauffer, D. L. and Seaman, N. L., Multiscale four-dimensional data assimilation, J. Appl. Meteorol., 33(3), 416-434, 1994.

Streets, D. G., Bond, T. C., Carmichael, G. R., et al.: An inventory of gaseous and primary aerosol emissions in Asia in the year 2000, J. Geophys. Res., 108, 8809, doi:10.1029/2002JD003093, 2003.

Takemura, T., Uno, I., Nakajima, T., Higurashi, A., and Sano, I.: Modeling study of long-range transport of Asian dust and anthropogenic aerosols from East Asia, Geophys. Res. Lett., 29, 2158, doi:10.1029/2002GL016251, 2002.

Torres, O. and Bhartia, P. K.: Impact of tropospheric aerosol absorption on ozone retrieval from backscattered ultraviolet measurements, J. Geophys. Res., 104, 21 569-21 577, 1999.

Twomey, S. A., Piepgrass, M., and Wolfe, T. L.: An assessment of the impact of pollution on global cloud albedo, Tellus, 36, 356366, 1984.

Uno, I., Wang, Z., Chiba, M., et al.: Dust model intercomparison (DMIP) study over Asia: Overview, J. Geophys. Res., 111(D12), D12213, doi:10.1029/2005JD006575, 2006.

Uno, I., He, Y., Ohara, T., Yamaji, K., Kurokawa, J.-I., Katayama, M., Wang, Z., Noguchi, K., Hayashida, S., Richter, A., and Burrows, J. P.: Systematic analysis of interannual and seasonal variations of model-simulated tropospheric $\mathrm{NO}_{2}$ in Asia and comparison with GOME-satellite data, Atmos. Chem. Phys., 7, 16711681, 2007,

http://www.atmos-chem-phys.net/7/1671/2007/.

van Aardenne, J. A., Carmichael, G. R., Levy, H., Streets, D., and Hordijk, L.: Anthropogenic $\mathrm{NO}_{\mathrm{x}}$ emissions in Asia in the period 1990-2020, Atmos. Environ., 33(4), 633-646, 1999.

van Donkelaar, A., Martin, R., and Park, R. J.: Estimating ground-level $\mathrm{PM}_{2.5}$ using aerosol optical depth determined from satellite remote sensing, J. Geophys. Res., 111, D21201, doi:10.1029/2005JD006996, 2006.

von Hoyningen-Huene, W., Freitag, M., and Burrows, J. B.: Retrieval of aerosol optical thickness over land surfaces from top-of-atmosphere radiance, J. Geophys. Res., 108(D9), 4260, doi:10.1029/2001JD002018, 2003.

von Hoyningen-Huene, W., Kokhanovsky, A., and Burrows, J. B.: Retrieval of particulate matter from MERIS observations, Advanced Environmental Monitoring, edited by: Kim, Y. J. and Platt, U., Springer, Frankfurt, 190-202, 2007.

Wang, J. and Christopher, S. A.: Intercomparison between satellite- 
derived aerosol optical thickness and PM2.5 mass: Implications for air quality studies, Geophys. Res. Lett., 30, 2095, doi:10.1029/2003GL018174, 2003.

Weaver, C. J., Ginoux, P., Hsu, N. C., Chou, M-D., and Joiner, J.: Radiative forcing of Saharan dust: GOCART model simulations compared with ERBE data, J. Atmos. Sci., 59(3), 736-747, 2002.

Woo, J., Streets, D., Carmichael, G. R., et al.: Contribution of biomass and biofuel emissions to trace gas distributions in Asia during the TRACE-P experiment, J. Geophys. Res., 108(D21), 8812, doi:10.1029/2002JD003200, 2003.
Zhang, Y., Pun, B., Vijayaraghavan, K., Wu, S., and Seigneur, C.: Community Multiscale Air Quality-Model of Aerosol Dynamics, Reaction, Ionization, and Dissolution (CMAQ-MADRID): Technical documentation. EPRI, Palo Alto, CA, 1005239, 2002. Zhang, Y., Pun, B., Vijayaraghavan, K., Wu, S.-Y., Seigneur, C., Pandis, S. N., Jacobson, M. Z., Nenes, A., and Seinfeld, J. H.: Development and application of the Model of Aerosol Dynamics, Reaction, Ionization, and Dissolution (MADRID), J. Geophys. Res., 109, D01202, doi:10.1029/2003JD003501, 2004. 